\title{
STUDYING THE PRACTICAL RATIONALITY OF MATHEMATICS TEACHING: WHAT GOES INTO “INSTALLING” A THEOREM IN GEOMETRY?
}

$\begin{array}{rll}\begin{aligned} \text { Patricio Herbst, } \\ \text { University of Michigan }\end{aligned} & \begin{array}{l}\text { Talli Nachlieli, } \\ \text { Levinski College } \\ \text { of Education, }\end{array} & \begin{array}{l}\text { and Daniel Chazan } \\ \text { University of Maryland } \\ \text { Israel }\end{array}\end{array}$

\section{Abstract}

This paper presents a way of studying the rationality that mathematics teachers utilize in managing the teaching of theorems in high school geometry. More generally, the study illustrates how to elicit the rationality that guides teachers in handling the demands of teaching practice. In particular, it illustrates how problematic classroom scenarios represented through animations of cartoon characters can facilitate thought experiments among groups of practitioners. Relying on video records from four study group sessions with experienced teachers of geometry, the study shows how these records can be parsed and inspected to identify categories of perception and appreciation with which experienced practitioners relate to an instance of an instructional situation. The study provides initial evidence that supports a theoretically-derived hypothesis, namely that teachers of geometry as a group recognize as normative the expectation that a teacher will sanction or endorse those propositions that are to be remembered as theorems for later use. In interacting with a story in which students had proven a proposition that the teacher had not identified as a theorem, the study also shows the kind of tactical resources that teachers of geometry could use to make it feasible for students to reuse such a proposition.

\footnotetext{
${ }^{1}$ The research reported in this article is supported by NSF, grant ESI-0353285 to the first and third authors. Opinions expressed here are the sole responsibility of the authors and do not reflect the views of the Foundation.
} 


\section{STUDYING THE PRACTICAL RATIONALITY OF MATHEMATICS TEACHING: WHAT GOES INTO “INSTALLING” A THEOREM IN GEOMETRY?}

\begin{tabular}{|r|l|l|}
\hline Patricio Herbst, & Talli Nachlieli, & and Daniel Chazan \\
\hline University of Michigan & $\begin{array}{l}\text { Levinski College } \\
\text { of Education, } \\
\text { Israel }\end{array}$ & University of Maryland \\
\hline
\end{tabular}

This paper illustrates a way of eliciting what we call the practical rationality of mathematics teaching. Following Herbst \& Chazan (2003) and building on Bourdieu's (1990) work on the logic of practice we hypothesize that a teacher's actions in an instructional situation are modulated by a practical rationality, a feel for the game, which an outside observer might describe as dispositions to act in certain ways. These dispositions, as described by an external observer, or the "categories of perception and appreciation" of teachers (Bourdieu and Wacquant, 1992, p. 11) consist of descriptions of perceptions of the moments, actions, people, and objects that are salient to members of a practice in a situation in which they practice. Practical rationality consists also of the principles or values that members of a practice use to justify or otherwise discard possible actions in an instructional situation.

To be clear, we do not suggest that this practical rationality dictates a particular course of action in a particular event. Rather, this rationality describes what is perceived in instruction and outlines boundaries between what it is reasonable, or customary, for a teacher to do and what is deemed as 'out of bounds.' At present we are interested in characterizing the sets of dispositions that are available to a group of practitioners, for example those who teach a same course of studies; we expect that latter work may take us to inspect individual differences. The present contribution zooms into an instructional situation in the teaching of high school geometry and illustrates a technique we have designed to elicit the practical rationality that a group of teachers had available 
to handle one of the demands of that instructional situation. This technique includes the use of animated scenarios that display instruction that departs, in places, from what is customary; groups of teachers experienced in geometry confronted one such scenario, and we analyzed their comments in search for elements of the practical rationality of geometry instruction.

In this paper, we concentrate on the instructional situation of installing a new theorem in high school geometry. We ask, what dispositions modulate the work of a teacher "installing" an item of knowledge in class? In particular, what dispositions frame the work of making a geometric statement part of the public knowledge (Ball \& Bass, 2000) that can be used later in justifying other claims? In institutionalized mathematics instruction, the tacit contract between a class of students and their teacher about a course of studies includes the expectation that students will come to know particular items of knowledge at some point during the time of those studies. After that point, students can be held accountable for having and using such item of knowledge. ${ }^{2}$ In this sense we say that an item of knowledge (a definition, theorem, postulate, or algorithm) has been "installed" in a class, when a teacher is entitled to consider that students in a class can be held accountable for using that knowledge. And we use the words "installing" and "installation" to refer to the work that a teacher and her class do to install an item of knowledge.

An important question that instantiates the notion of practical rationality in geometry instruction is what dispositions undergird experienced teachers' work of installing an item of knowledge. This question is important especially because recommendations for practice put a premium on students' active participation in the development of mathematical knowledge that is new to them. Thus the question attempts to elicit what dispositions could support (or constrain) devolving more of the work of installing a theorem to students, while still entitling the teacher to

\footnotetext{
${ }^{2}$ Note that installation does not mean the same as learning since students might be held accountable for knowing something, while at the same time some individual students might not actually be able to use that knowledge.
} 
hold students accountable for knowing and being able to use the target item of knowledge. Though much typical instruction is premised on the notion that teachers must take full responsibility for installing new knowledge, there are examples of teachers who have sought to devolve some of that work to students (see Fawcett, 1938; Healy, 1993). The question of how much responsibility could be shared with students for the installation of new knowledge has been studied from the perspective of the design of learning (e.g., see Brousseau, 1997; also Balacheff, 1991). In particular the notion of an adidactical situation of validation where students develop and recognize new knowledge through adapting to the demands of their milieu has been proposed to frame that research.

This paper complements the perspective of designers of learning by inquiring into the perspective of the teacher and the rationality that animates the teacher's practice. Our question is what dispositions could be available for teachers to use in figuring out how to handle, in practice, the responsibilities that they customarily have in the installation of new knowledge. We investigate this question for the particular case of the installation of theorems in the high school geometry class. To further illustrate what we mean by installing a theorem, we invite the reader to consider the following story. ${ }^{3}$

In a high school geometry class, a student (Rho) shows the answer to a homework problem (problem 33). The problem includes a diagram of an isosceles triangle $(\triangle A B C)$ and the "Given: $\overline{A B} \cong \overline{A C}$ " and "Prove $\angle B=\angle C$." A hint ("Draw a median to $\overline{B C}$ ") is provided (see Figure 1a). The student provides a proof and goes back to her seat (see Figure 1b). The teacher notes that the class should make sure they understand what Rho has done. After finishing the review of the rest of the homework, the teacher assigns a new problem, "Prove that by connecting the midpoints of an isosceles triangle, one gets another isosceles triangle." On the board the teacher draws a triangle $\triangle A B C$ and writes: Given: $\overline{A B} \cong \overline{B C}, D$, $E$ and $F$ are midpoints (of the sides of $\triangle A B C$ ). Prove: $\triangle D E F$ is isosceles (see Figure 1c). Students work on the problem in pairs. When the teacher calls on students to show what they did, students Lambda and Kappa say that they have drawn a median to the base of the given isosceles triangle, proved that the base angles are congruent, and used that to show that triangles $A D F$ and $C E F$ are congruent. Using that idea, those students have shown that

\footnotetext{
${ }^{3}$ The reader may also watch an animation of this scenario in ThEMaT Online, http://grip.umich.edu/themat, selecting the Isosceles Triangles story.
} 
$\triangle D E F$ is isosceles. Another student complains that the problem was long. Yet another student notes that they had looked ahead in the book and saw the base angles theorem, which they thought would be useful, but they did not use it because they had not covered it yet. The teacher is distressed by the fact that no student has used the result they proved for homework. Frustrated, he says that the problem "could have been much shorter" and asks Rho to remind the class of the result she had proven and which the teacher seems to think could have been used here to justify steps in the proof. But Rho seems not to remember the result she proved!

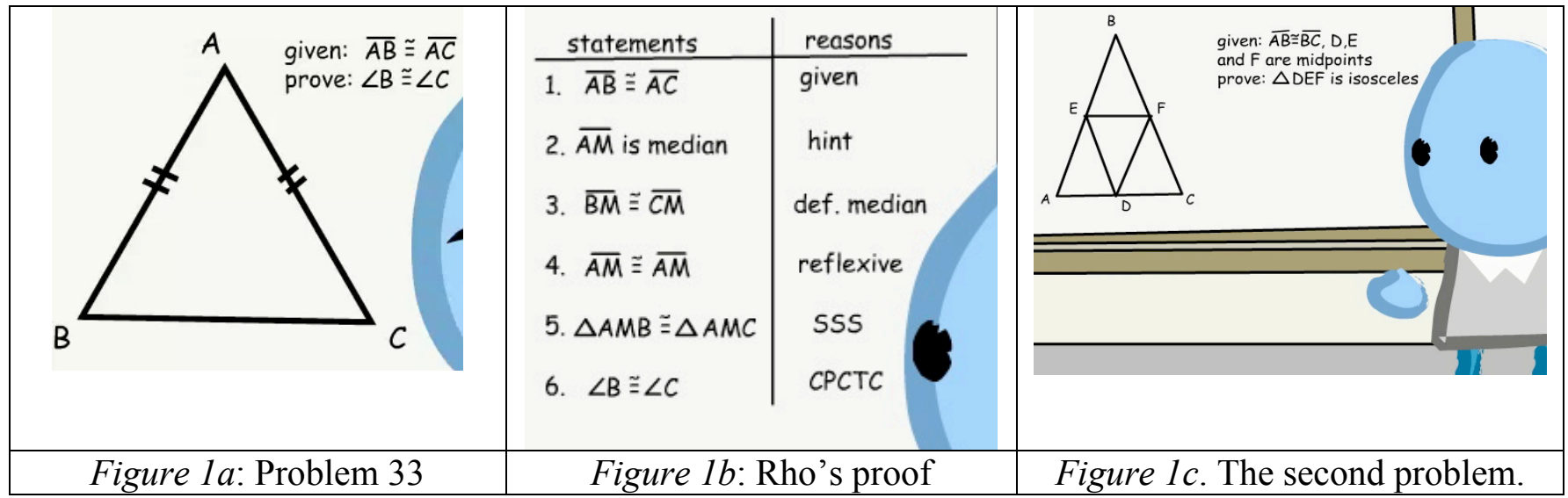

In this scenario, the teacher expects that his students use, as a theorem, the result that if a triangle is isosceles, the angles opposite the congruent sides are congruent. That expectation is not met. The story helps ask: Is this teacher's expectation reasonable? If not, what would teachers consider this teacher had to do in order to deem it reasonable for him to expect students recognized the result proved and use it as a theorem? Evidently, one possible answer is that the teacher could spell out a theorem $\mathrm{X}$ and then say to students "use the theorem $\mathrm{X}$ in problem Y." But considering that it is desirable for students to be agents in the construction of knowledge, what do teachers consider a teacher needs to do to be able to fairly expect that students identify the proven result as a theorem and know that they can use it as such? If the rationality of the practice sets as the default expectation for teachers to sanction memorable statements as "theorems," how could a teacher handle departures from such a default setting and still avail him or herself of the right to consider a proposition to have been installed as theorem, and thus usable by students in the ways that theorems are used? The question is particularly pressing when reformers expect teachers to share 
responsibility with students for the development of new knowledge - when it is important to enable students to be autonomous with regard to knowledge. It is known that students have the capacity to make discoveries and that learning environments can be created for them to do that (e.g., Schwartz, Yerushalmy, \& Wilson, 1993). But a teacher's responsibility goes beyond supporting the emergence of ideas; it includes ensuring that students consider those ideas knowledge, using them as instruments in further intellectual pursuits. To support the work of a teacher installing a theorem, a teacher needs more than exhortations "not to tell" (Chazan \& Ball, 1999). And yet, from a disciplinary perspective on mathematics one could think, ${ }^{4}$ as one might imagine the teacher in the story did, that if a result has been proven it could be used to prove new results. Particularly in the American high school geometry class, where students are explicitly inducted into an organization of knowledge that puts a premium on establishing true propositions by proving them, one might think that students should have no doubt of the truth of the result the student has proved (unlike students in Williams, 1979).

In showing animated versions of that story to teachers, as researchers, we are interested in understanding how teachers of geometry talk about why students in the story failed to use the proved result and what the teacher might have done to prevent such failure. We use their responses to that story (1) to confirm that, as a group, teachers of geometry perceive there is an expectation for them to sanction a statement as theorem in order to consider it installed as knowledge and (2) to elicit the possible moves that a teacher could make to depart from such a default expectation and allocate greater agency to students. From the latter moves, we distill some of the dispositions of practical rationality--what teachers perceive as alternative actions in that story and how those possible actions could be justified.

\footnotetext{
4 This thought overlooks what Davis \& Hersh (1981) argue - that the social shapes what is installed as a theorem in the discipline.
} 
Theoretical Framework: Practical Rationality and Instructional Situations

Practical Rationality's Relation within the Research on Teaching Literature

The literature on teaching abounds in words and approaches that have been used to (1) describe the actions that teachers take and (2) identify the set of resources with which teachers warrant their action. Observers of classroom interaction have described teacher's actions using constructs such as the notion of a cultural teaching "script" (Stigler and Hiebert, 1999; Santagata and Barbieri, 2005), patterns and routines of classroom interaction (Bauersfeld, 1988; Mehan, 1979; Voigt, 1985), activity types or activity structures (Leinhardt \& Greeno, 1985; Lemke, 1990), problems of teaching (Lampert, 2001), and ventures, moves, and strategies (Cooney, Davis, and Henderson, 1975; Smith, Meux, et al. 1962).

The resources with which teachers warrant what to do have been identified with the assistance of a number of germane notions including Schoen's (1983) knowledge-in-action and reflection-in-action, Leinhardt's (1990) craft knowledge, Shulman's (2000) wisdom of practice, Fenstermacher's and Richardson's (1993) practical argument, Doyle \& Ponder's (1977/1978) practicality ethic, and various approaches to teacher beliefs (in mathematics and its teaching; e.g., Ernest, 1991; Leder, Pehknonen, and Törner, 2002; Philipp, 2007; Speer, 2005). Also several notions of teacher knowledge have been proposed including Shulman's (1986) pedagogical content knowledge, and various conceptualizations of mathematical knowledge for teaching (Ball, Lubienski, and Mewborn, 2001; Ball, Thames, and Phelps, 2008; Even, 1990; Silverman \& Thompson, 2008; Thompson \& Thompson, 1996). The distinction between professed beliefs and attributed beliefs has been used to account for the relationship between those resources and pedagogical action (Törner, 2002) and researchers have found consistencies as well as inconsistencies between what teachers profess and what they do (see Cohen, 1990; Raymond, 1997; Thompson, 1984, 1992). 
In an attempt to pull together the literature on the resources with which teachers warrant their actions, Schoenfeld $(1999,2006)$ has proposed a way of modeling individual teachers' actions, described at different levels of granularity, as responding to their beliefs, goals, and knowledge; this has added to earlier literature on teacher decision-making (e.g., Shavelson and Stern, 1981; Borko and Shavelson, 1990). As can be noted, the literature that explores the connections between teacher thinking and action in the last four decades is vast. It is also a diverse literature not only in the constructs and underlying theoretical commitments but also in the methods and techniques that it uses.

While an organized review of that large body of literature is beyond the scope of this paper, we make three synthetic observations about that literature that help us identify the nature of our contribution to existing theory and research. A first observation is that most accounts of the relationship between teacher thinking and action (e.g., Schoenfeld, 1999) have focused on teachers as individuals who enact their personal goals, knowledge, or beliefs in actions in which they are relatively autonomous. A second observation is that a large part of that literature that links teacher thinking with action has relied on techniques (such as the interview, the questionnaire, or the stimulated recall) that presume the explicitness of that thinking for the practitioner. Exceptions to this observation include the investigations of teaching that examined teacher narratives (e.g., Clandinin and Connelly, 1996) and the use of individual teachers' responses to similes and metaphors of teaching (e.g., Cooney, Shealy, and Arvold, 1998). A third synthetic observation is that by and large the literature has not systematically examined the rationality of mathematics teaching in specific situations but has rather taken the teaching of a lesson or of an individual teacher as a relatively homogeneous locus where a general rationality applies. We see this present in the attempts to describe actions as expression of different kinds of teaching (traditional, reform; Boaler, 2002; Cobb, Wood, Yackel, and McNeal, 1992) or expression of different cultures of 
teaching (Stigler \& Hiebert, 1999). A notable exception of this is the cognitive modeling of teaching approach of Leinhardt \& Greeno (1985) focused on activity structures.

In our research program on the practical rationality of mathematics teaching, we start from a set of assumptions that is more in line with the descriptive literature on teacher practice. We view mathematics instruction as a practice, done recurrently by people playing specific roles (Buchmann, 1986). The conditions in which this practice is enacted issue specific obligations to those in the role of teacher-in particular, obligations to the discipline whose knowledge is the subject of instruction, to the individual students who are there to learn, to the classroom space and community as a public channel of interaction, and to the instructional setting and processes of schooling (schedules, assessments, curricula, etc.). We hypothesize that those obligations have an influence on what practitioners do, even if practitioners are not able to articulate consciously the effects of these obligations. For example, in our view, as in other practices, experienced geometry teachers figure out what to do by a combination of goal-oriented strategies and tactical responses to events in context.

Our approach contributes to the extant mathematics education literature on the relationship between teacher thinking and their action by highlighting normative elements with which a professional collective (such as the teachers of a particular course of studies, taken as a group) could endorse, accept, or disown, actions by a purported member of such collective. This collective perspective complements the literature's focus on individual teachers by exploring the customary practices of teaching into which individuals are socialized and the rationality behind them. We are interested in understanding what principles could possibly justify or indict actions that deviate from what is expected within the discourse of a collective, rather than the personal motives or reasons for individual teachers to choose some actions over others (see Buchmann, 1986). 
Second, our data collection technique - the triggering of practitioners' reactions to narratives of practice represented through animations of cartoon characters - builds on the narrative inquiry paradigm as well as on the ethnomethodological notion of breaching experiment and enable us to unearth usually tacit elements of rationality. In that sense we contribute to the arsenal of methods that could be available for the study of teachers (see also Jacobs and Morita, 2002). Inasmuch as some of the elements that help explain teaching action are tacit, it is important for the field to have techniques that elicit them without a mediating process in which they become explicit (which would be the case using survey instruments). Third, while we are not necessarily intent in deconstructing the notion that the rationality of teaching has components that operate on teaching mathematics in general, we provide a way of examining how the rationality of teaching operates in instructional situations within specific courses of study. Along these lines, our technique of eliciting teachers' reactions to animated or cartoon-based stories that prototype instructional situations helps unearth situated elements of this rationality in ways that improve upon other possible tools such as the written vignette. To the extent that the cartoon-representation of people and settings can be controlled to abstract some elements of context and focus on chosen elements of practice, our technique appears to be more malleable than video for the development of research instruments. Furthermore, the facility with which many developments of a classroom episode can be represented in the same graphic language presents an advantage over other means of representing alternatives in teaching (such as offering a video record and a written description of an alternative) in the sense that all possible developments of an episode can be presented on comparable terms (see also Herbst, Chazan, Chen, Chieu, and Weiss, in press). Our bet is that a combination of situation-specific and profession-general regulations would eventually help account for action in mathematics teaching; 
this paper however presents a first approximation focused on the situation of installing a theorem in high school geometry.

Building on Pierre Bourdieu's notion of habitus (or practical reason; see 1998) we use the expression practical rationality to refer to the categories of perception and appreciation with which teachers talk about how they handle the demands of their work, and the dispositions that, as a result, observers ascribe to teachers' actions. ${ }^{5}$ By proposing that term, practical rationality, we postulate that the practice of teaching mathematics is regulated by knowledge and principles that derive from professional obligations on the position of the teacher and the demands on the role the teacher needs to play in specific contracts and instructional situations. Further, we hypothesize that while some of those regulatory elements are explicit, many others are tacit (Cook \& Brown, 1999; Linde, 2001); while some elements are strategic (goal-oriented), others are tactical, adaptable to respond to immediate context. We are presently concerned with the content of practical rationality rather than its locus of control and change (the individual agent, the professional collective, the policy makers) or its ontogenesis. We speculate that practical rationality may exist as a result of development by adaptation to the demands and affordances of a specific kind of work and used to handle those demands. And, for that reason, we hypothesize that practical rationality is first and foremost a characteristic of a practice, not reducible to individual differences. This hypothesis helps us understand how the actions of teachers, diverse as they may be from some points of view, all bear the imprints of schooling in order to be viable actions on the part of a teacher in the social setting we call school. In what follows we develop a theoretical perspective to conceptualize what we mean

\footnotetext{
5 Philosopher of education Thomas Green (1976) also alluded to "practical rationality" but without a definition. And Immanuel Kant (see Reath, 2006) used "practical rationality" also but while his interest seems to have been on the structure and logic of practical reason, our interest is in its content.
} 
above by the demands of the role the teacher needs to play in specific contracts and instructional situations.

\section{A Theory of Instructional Exchanges}

The responsibility to teach a particular mathematical domain (such as algebra or geometry) to high school students in school classrooms places the teacher in a set of global relationships with the subject matter and the students (Cohen, Raudenbush, and Ball, 2003). Those relationships operate like a contract particularly defining role relationships between teacher and students vis-à-vis the subject of studies (Brousseau, 1997; Herbst, 2002, 2003): In general, for high school geometry, the contract says that the geometry teacher must teach geometry to his or her students and shares responsibility with them for their learning of geometry. The contract embodies obligations to the discipline of mathematics, to students as individuals, to the general processes of school instruction (its schedules and assessments), and to social interaction (that of the class as a group) - see Herbst \& Balacheff (2009). Any institutionalized instruction has a contract that ties teacher, student, and subject matter by providing a general interpretation of those obligations, enforced through the particular custom of a class (Balacheff, 1999). In particular any contract is a contract for transactions about a more or less well defined body of knowledge. For example, the mainstream contract for the US high school geometry course ${ }^{6}$ includes, in particular, the customary obligation to represent geometry as a system of theorems and definitions derived deductively from postulates and basic terms and the customary obligation to develop in students knowledge of those definitions and theorems and their connections, and the more general capacity to reason deductively. More generally (shared with other school courses) contractual norms are likely to exist to regulate

\footnotetext{
${ }^{6}$ At various points in time there have been calls for laboratory geometry courses that follow inductive or informal approaches to the subject, We consider those as different contracts which are not addressed in this study.
} 
interaction about knowledge-for example the notion that the teacher has the right to ask knowledge questions to students and expect an answer in return.

Against the background of that general contract, concrete instances of mathematical work, including mathematical tasks, happen day-to-day and moment-by-moment. Novel tasks might require the teacher and students to negotiate explicitly how their class contract applies to those tasks (that is, what it is that people need to do to teach and learn the knowledge at stake in that particular task; see Herbst, 2003). Yet quite often, classroom activity goes forward smoothly_without explicit discussion, people act as if they knew what they are supposed to do in order to play their role in the contract.

One specific class of items of the high school geometry contract are geometric theorems (true and important statements that articulate geometric theory): Theorems need to be represented faithfully and they need to be learned and used by students as reasons in justifying new claims (Senk, 1989). We are interested in what it is that teachers tacitly accept responsibility for doing, what they expect they have to do when the representation and the learning of a theorem are at stake.

Herbst (2006) has proposed that the didactical contract is elaborated and enforced in the context of instructional situations--particular frames (Goffman, 1974) of activity where students and teacher can trade some of the work they do together (e.g., in the context of a specific kind of mathematical task) for claims that students have had opportunities to learn about a specific (kind of) object of study prescribed in the contract (say through the syllabus). The notion of an instructional situation is useful to understand the particular position of the teacher who often has to manage interactions with students not only strategically (i.e., oriented to the procurement of contractual goals) but also tactically (i.e., adapting to the give and take of human interaction). An instructional situation can be understood as a system of norms (or tacit requirements) that regulate a particular 
kind of exchange or trade between two kinds of goods. One kind of goods is the actual work that teacher and students do together to sustain their mutual relationship with content-materialized in the form of talk and action, moment-by-moment. The other kind of goods are the mathematical knowledge and the students' learning of them that a teacher needs to lay claim on-a teacher needs to be able to say that such-and-such idea has been taught or that students have had the opportunity to learn that idea.

Instructional situations facilitate the management of that exchange by framing chunks of interaction. Specifically, we hypothesize that classroom life is organized in segments of interaction whose goal is to produce mathematical work and exchange it for claims on the knowledge at stake. Examples of instructional situations include "doing proofs" (Herbst et al., 2009) in high school geometry and "solving equations (in one variable)" in algebra I (Chazan \& Lueke, 2009). In this paper we use the situation that we call "installing a theorem" in high school geometry (see Herbst \& Miyakawa, 2008) as a context to study the practical rationality that assists teachers in handling the demands of that situation. As noted in Herbst et al. (2009; see also Nachlieli and Herbst, 2009) part of our work includes modeling instructional situations by making hypotheses about what those situations customarily require. We call those requirements norms to underscore that they are requirements the situation makes of participants. Everything happens as if participants held themselves accountable to fulfill them even though such accountability is tacit and their actions may somehow deviate from the norm. Norms are thus neither ineluctable like physical laws nor compulsory like the rules of a game. They rather are defaults, or tacit expectations about behavior that if done, would go without saying (see Bourdieu, 1990).

In this article we examine the situation of "installing a theorem" in the mainstream, US high school geometry course. We make the hypothesis, grounded in observations of a large corpus of 
high school geometry lessons, that to install a statement as usable knowledge, teachers recognize as a default their responsibility to sanction a statement as theorem-that is teachers expect that they will have to attribute a status, such as theorem (or property), to the target statement that students are to learn (and use). The main contribution of this article is to show a technique that can elicit from teachers the elements of practical rationality that they have available, as a collective, to handle (comply with, depart from) that norm. This technique, which we describe below, builds on ideas from the ethnomethodological tradition (Garfinkel \& Sacks, 1970).

We contend that in order to know whether and how instructional practices can be changed (e.g., whether new theorems can come from students' work on problems; see Lampert, 2001), we need to better understand how practical rationality works to sustain and organize customary instructional practices. The notions of situation and of norm of a situation are valuable insofar as they help design ways of uncovering that rationality and explaining how that rationality works. If we compare teaching with dance, situations and norms are comparable to the possibilities and limitations of human body posture and movement, but knowledge of those is only background for the choreographer to compose a ballet or for the critic to assess a performance. Thus, when we are concerned with improving or assessing teaching, the focus is on assessing or improving the resources for action; norms and situations are instruments to understand and shape those.

\section{Method}

\section{Hypothetical Norms and Breached Representations}

To understand the rationality that undergirds the work of a teacher of geometry installing a theorem we start from hypothesizing norms that describe the instructional situation of interest. We reiterate that what we mean by a norm is a statement of one of the demands or controls that affects the way a role (the teacher, in this case) is played in an instructional situation. The norm might be 
attributed if classroom participants (teachers, in this case) acted as if they held themselves accountable to do what the norm says whenever they acknowledge being in a given instructional situation. Such approach could document the frequency of behaviors consistent with a norm and thus provide evidence that, at best, would give no grounds to reject the existence of a norm yet not necessarily capture the extent to which a norm exists that compels participants to act in such ways. We propose an alternative technique of eliciting norms that helps document that compulsion. Our technique relies on conceptualizing norms as expectations of default behavior that, were they to take place in an instance of an instructional situation, they would go without saying but were they to be breached, they would elicit ad hoc "repairs" (which we elaborate on below). For this investigation we hypothesized as a norm that if a teacher will be able to hold students accountable for using a theorem (i.e., for teachers to be able to assume that a statement has been installed as theorem), the teacher will have to sanction (or endorse) the statement of interest by investing it with the special status of theorem (also property or lemma). ${ }^{7}$ The method we introduce is not only suited to confirm that such norm exists, but also, and more importantly, to elicit from teachers the categories of perception and appreciation available for them to construct possible alterations to the default actions stipulated by the norm. ${ }^{8}$

We use that hypothesized norm of the instructional situation of installing a theorem to create an experimental probe with which to study the practical rationality behind teachers' management of the situation. To do this we build on the ethnomethodological tradition of "breaching experiments" (Mehan \& Wood, 1975) in which models of practical actions are put to empirical test by creating practical circumstances (experiences) that instantiate the situation under study but where a norm has

\footnotetext{
${ }^{7}$ The making of such hypothesis is grounded in a corpus of geometry lessons in four intact classrooms where most times that a theorem is installed the teachers sanction it as such.

${ }^{8}$ We note also that in making this hypothesis we mean neither to subscribe nor to object to the norm. This is a norm that (we hypothesize) underlies practice as it exists regardless of our opinion of it.
} 
been purposely breached. The experiment consists of engaging individuals who are experienced participants of the situation being modeled and observing whether and how they react to the breaches of the norm included in the experience. The purpose of studying those reactions is twofold. First, the hypothesized norm can be confirmed by observing whether participants respond to their breach. Second, by examining what participants say in response to such breaches, the role of the norms can be explored so as to better understand, from the practitioners' perspective, what keeps those norms in place and what resources practitioners have to handle them (and perhaps depart from them). While the breaching experiments of ethnomethodologists originally immersed participants in real, but breached, social situations, our approach consists of confronting practitioners with representations of classroom events realized with animations of cartoon characters.

\section{Thought Experiments with Groups of Practitioners}

To explore teachers' practical rationality apropos of the situation of installing a theorem, we created experiences in which practitioners confronted the classroom story narrated above, which had been represented through an animation of cartoon characters. The story can be seen as an (unsuccessful) attempt at the "installation" of a theorem: The teacher in the story acts as if the students should be able to use the result proved in the homework to solve the problem of the day, but the students act as if what they proved before is not a result that they could use.

The story also helps illustrate the technique we use to elicit teachers' views about what is involved in the work of managing the installation of a theorem: The story has many features that make it a conceivable story from a US geometry classroom, but in particular it probes the hypothesized norm by showing actions that depart from what the norm stipulates the teacher to be expected to do. In particular, while in the story the students prove a useful result, the teacher does not sanction it as a theorem, and yet he expects them to use it in the following problem. Based on 
our hypothesis, for the teacher to be entitled to expect his students to use the prior result in the following problem, he would have had to do more than overseeing the proof of the result. In particular, he would have needed to sanction the statement as theorem.

Thus the story illustrates our technique in the following way: The story embodies a piecemeal alteration of what, we hypothesize, is normative in "installing a theorem." We contend that the story can be used as a probe to study specifically whether such hypothesis describes an aspect of the role teachers are expected to play in installing a theorem and what elements of practical rationality sustain that demand. Specifically, we contend that by immersing practitioners in the story we can observe how they relate to events in this story and thus add credence to, or refute, the hypothesized norm. More importantly, the discourse that practitioners engage in when they address those problematic events may help us understand their perspective on what role the norm plays in the instructional situation and what resources practitioners have available, as a collective, to warrant acting in consonance with the norm or otherwise departing from it.

To be able to immerse practitioners in stories like the one narrated at the beginning, we have produced stories as animated movies of cartoon characters. We have used them to prompt groups of practitioners to talk about how they manage instructional situations in the geometry class. Central to this technique is that these practitioners recognize themselves as being subject to the same demands as the teacher whose records they confront (e.g., they also have to teach the base angles theorem in a high school geometry course) and can hold each other accountable to responding to the demands of their professional position. In this sense, the use of these materials with groups of teachers affords something that we believe would not be afforded by having individual participants respond to the same materials: It affords conditions that can precipitate and enforce a professional discussion of what practitioners perceive they are expected to do by the demands of their role (rather than what 
they personally would like to do; see Buchmann, 1986). A thought experiment in mathematics teaching by a group of participants provides less of a view on what each individual believes (which we are not focusing on at present) and more of what the practice (as approximated by a group of experienced practitioners) requires or allows them to do.

Central to our methodology is a stance on this group discourse as an emergent debate about the practice that the participants share. We expect that the homogeneity of the group shape what can be said in the group (e.g., there are some things they take for granted by virtue of their assumed common experiences, non-standard views must be marked as such). We conceptualize the discourse in a study group as the product of the group, where participants adapt what they say to the particular conversation they are having; the discourse is not conceptualized as produced by a juxtaposition of individuals each of which makes independent, individual comments. More importantly, we are interested in what gets said, rather than in who says it. Thus, we do not seek to establish the strength of a norm by the number of people whose utterances seem to support the norm, but instead by examining what is said and how often, as well as what is not said.

While the present study's focus on groups of practitioners shares that feature with earlier papers (Herbst \& Chazan, 2003; Nachlieli \& Herbst, 2009; Weiss, Herbst, \& Chen, 2008), this one offers an application of the same technique for the study of a different instructional situation, installing a theorem. The present study adds to that focus the use of video prompts generated with animated cartoon characters. The details of how those cartoon characters have been designed and the argument for their use instead of video is a matter is beyond the scope of this paper (but see Chazan \& Herbst, in review; Herbst \& Chazan, 2006; Herbst \& Miyakawa, 2008).

Our method is thus based on the assumption that the confrontation of a relatively homogeneous group (experienced high school geometry teachers) against an atypical, but 
conceivable, way of meeting an obligation specific to their job can be used to elicit data that helps study the practical rationality related to the sanctioning-of-a-theorem norm hypothesized above. Conversations in which teachers offer and consider alternative courses of action that might fulfill the same obligation, but prevent the problems they perceive being raised in the story under consideration, conversations in which they discuss whether and why one alternative might be better than another are what we call "thought experiments in mathematics teaching."

We contend that such thought experiments - encounters of a group of practitioners who are all responsible for similar curricular obligations with an atypical instance of a way to meet such obligation - are the kind of experiments in teaching that can lead us to understand what kind of practice teaching is (Cohen, 2005). Specifically, the discourse produced by teachers in response to an atypical story of their practice, the discourse where they remark upon the events of a story to negotiate the conditions in which the story could be a representation of their practice, can contain the categories of perception and appreciation that span the practical rationality on which actual performances of their teaching are grounded.

\section{The Data that Can be Generated with this Technique}

Our theory enables us to predict that a classroom story where a teacher laid claim on the installation of a theorem without having complied with the sanctioning norm would elicit repairs (ad hoc commentaries denouncing the scenario) on the part of those teachers of geometry who viewed their "colleague" frustrated by his students' actions.

We predicted that participants who were experienced in installing theorems would produce ad hoc remarks that would either repair the situation (i.e., explain that what had been done could not have been a case of installing a theorem or cast the episode as an instance of a different situation), or repair some of the tasks of the teacher or the student enacting the situation (i.e., 
explain how some of the things done would have needed to be done differently for the episode to represent the installation of a theorem). In general, we expected teachers would act as if the animation said something to the effect of "this teacher thinks he has taught the theorem, but he has not." Specifically, we expected that participants would do such repairs by identifying moments in the story when something out of the ordinary had happened (or something ordinarily needed had not happened). We expected that, in confirming our hypotheses by way of those repairs, participants would disclose elements of their practical rationality. Specifically, we expected that in describing and allocating value to the events in the story, participants would make use of categories of perception and appreciation that are part of the practical rationality they use to organize viable action in installing a theorem, in particular outlining alternative courses of action that could have been followed. By categories of perception we mean the categories used by participants to describe objects, people, and actions involved in the story or in alternatives to the story. By categories of appreciation we mean principles and values used to argue for or warrant actions in the story.

\section{Data Collection Geometry Study Groups as Sites for Data Collection}

We recruited high school teachers with 3 or more years of experience teaching the geometry course and organized them into two parallel study groups that met monthly to discuss issues related to geometry instruction. ${ }^{9}$ The story "Isosceles triangles: A homework problem" was considered in parts of four sessions, two for each of the two different groups of participants. We refer to those sessions as ITH-111605, ITH-121505, ESP-011006 and ESP-020706; these names identify each of the groups and preserve the dates when the sessions were held. By the time these sessions were

\footnotetext{
${ }^{9}$ Study groups eventually met for two years and generated a large data corpus of over 120 hours of group discussion.
} 
held, participants had already been having conversations about teaching stimulated by animated cartoon characters for at least two months and were thus used to each other and to the media.

We use records of four of those sessions to show how the technique described in this article helps elicit empirical data. All of those meetings were video-recorded by two cameras that, combined, kept track of the facial expressions and movements of all members of the group in addition to recording the spoken words of everybody at the table. In each of the sessions, a staff member acted as moderator while one or two other staff members sat at the table with a group of teachers playing the role of provocateurs. These staff members were asked to play complementary roles: While the moderator had the role of making participants feel comfortable sharing their opinions and maintaining the continuity of the conversation, the provocateur or researcher was expected to probe comments that might inform the research questions of the study (see Nachlieli \& Herbst, 2010; Nachlieli, in review). The teacher participants in sessions ITH-111605 and ITH121405 included Cynthia, Denise, Edwin, Glen (absent for ITH-111605), Megan, Penelope, and Tina (all pseudonyms). They came from a diverse set of school districts-Penelope, Tina, and Megan came from three different urban districts; Denise came from a blue-collar suburb and Edwin from an affluent suburb; Cynthia and Glen came from small towns. The participants in sessions ESP-011006 and ESP-020706 included Carl, Esther, James, Karen, Megan ${ }^{10}$, and Mitch (though Mitch was absent in the first one, and Carl and Karen were absent in the second one). Carl and Karen taught in the same urban district as Megan. James and Esther taught in two different small towns, and Mitch taught in a large urban district. They had been recruited under the premise that their participation in conversations about teaching would help collect the wisdom of practice.

\footnotetext{
${ }^{10}$ Megan had moved from the "Wednesday" to the "Tuesday" group after Christmas, so she participated of all four sessions. Some references were carried over from one set of discussions to the other because of this.
} 


\section{Parsing and Transcription of Records}

Video records from these study group sessions were synchronized and stitched together into a double-wide video screen that covered all the participants at all times. To preface the way we parsed or unitized the data it bears restating that we are not here interested in examining individual stances toward the scenarios shown in the animation, but rather in what are all the different things that the group had to say in response to it. Hence, rather than tracing what an individual contributed to a long series of short conversations, we were interested in mapping the content of this series of short conversations. The following articulates how we went about developing a unit of analysis that then would help us map the many conversations among these groups of teachers.

The video records were examined first by way of an analysis of interaction in which we parsed each three-hour record into units of analysis that we call intervals and that operationalize the notion that within a long meeting there are many smaller conversations. As a unit of analysis, intervals are, fundamentally, emic - that is intervals are constructed by the participants (through their actions) rather than specified by the observer. An interval consists of segments of group interaction that participants construct as units of conversation by way of employing a combination of the organizational features (inspired by what Hymes, 1977, suggests as defining characteristics of a communicational event in ethnography of communication) such as:

- Active Participants: An interval involves a subset of participants of the study group as active participants, whereas others are passive.

- Specialized division of labor in the conversation: The active participants stage a conversation that could be described as a conversational pattern, (e.g., storytelling, chit-chat; see Eggins and Slade, 2005) where they assume specialized roles (e.g., one is narrator, the others provide cues). The pattern might be described using body orientation (especially of peripheral members who give clues as to who they are attending to), time per turn per participant, etc.

- Participants may explicitly label the theme they are discussing (e.g., "I'd like to come back to Lynn's earlier comment") and moves of this sort can be useful to parse intervals.

- Special artifacts are used (e.g., an easel pad or a piece of paper) 
- Intervals are of the order of 2 to 8 minutes, though these are occasionally very short (a minute or so), or very long (more than ten minutes).

- Once we identify emic boundaries of intervals using the features noted above, and considering that those changes also take place over time rather than at a particular moment, we round the beginning and end points of intervals to include boundaries and round timecodes to the $5^{\text {th }}$ second below (viz. above).

- With these rules, intervals end up being not disjoint; rather, contiguous intervals share boundary periods.

- Changes in thematic content do not necessarily trigger a change of interval unless they are explicitly signaled as changes. Rather, interval parsing helps us size the posterior task of thematic content analysis.

Operationally, we identified intervals through looking for emic boundaries, that is those liminar moments when changes were made to one or more of the elements listed above. Intervals are multimodal units; whereas speech is the dominant mode of interaction, interaction is also done through facial expression, gesture, written text, drawing, and silence. We therefore relied on a transcript of verbal acts with the understanding that the analysis of the conversation based on interaction between a transcript and its accompanying video might generate improvements in the transcript. Within each interval we identified turns as the subunit of analysis and defined turn as the communications exchange while one individual holds the floor.

For the purposes of this paper, we have taken intervals as units of analysis and we have looked in intervals for evidence in support of our hypothesis that sanctioning a theorem is normative as well as evidence of the categories of perception with which participants relate to this norm. There were 147 intervals of the four recorded sessions in which the story "Isosceles triangles: A homework problem" was the intended focus of conversation. This includes intervals when participants watched the movie, discussed the story, considered or proposed alternatives to the story, narrated anecdotes of concurrent thematic content, or deviated momentarily but came back to the task. Of those 147 intervals, 125 contained participants' conversations while the remaining 22 
were ones in which participants were watching the animation. This corpus of 125 intervals is described in Table 1 where information is broken down by individual session.

Table 1: Summary statistics of parsing of each session conversations (*)

\begin{tabular}{|c|c|c|c|c|c|}
\hline Variable $\backslash$ Session & $\begin{array}{c}\text { ITH } \\
111605\end{array}$ & $\begin{array}{c}\text { ITH } \\
121505\end{array}$ & $\begin{array}{c}\text { ESP } \\
011006\end{array}$ & $\begin{array}{c}\text { ESP } \\
020706\end{array}$ & Total \\
\hline Number of Intervals & 47 & 19 & 52 & 7 & 125 \\
\hline Total Duration & $\begin{array}{c}1 \mathrm{~h} 39 \mathrm{~m} \\
18 \mathrm{~s}\end{array}$ & $\begin{array}{c}1 \mathrm{~h} 3 \mathrm{~m} \\
36 \mathrm{~s}\end{array}$ & $\begin{array}{c}2 \mathrm{~h} 34 \mathrm{~m} \\
54 \mathrm{~s}\end{array}$ & $20 \mathrm{~m} 48 \mathrm{~s}$ & $5 \mathrm{~h} 38 \mathrm{~m} 30 \mathrm{~s}$ \\
\hline $\begin{array}{l}\text { Average duration per } \\
\text { interval (in sec) }\end{array}$ & 126.7 & 200.8 & 178.8 & 177.9 & 162.5 \\
\hline $\begin{array}{l}\text { Median Duration per } \\
\text { interval (in sec) }\end{array}$ & 110 & 180 & 160 & 140 & 140 \\
\hline $\begin{array}{l}\text { Average number of } \\
\text { turns per interval }\end{array}$ & 18.7 & 21.9 & 28.5 & 29.6 & 23.9 \\
\hline $\begin{array}{l}\text { Median number of } \\
\text { turns per interval }\end{array}$ & 13 & 24 & 24 & 28 & 21 \\
\hline $\begin{array}{l}\text { Average number of } \\
\text { speakers per interval }\end{array}$ & 5.4 & 5.2 & 5.8 & 4.4 & 5.5 \\
\hline $\begin{array}{l}\text { Median number of } \\
\text { speakers per interval }\end{array}$ & 5 & 6 & 6 & 4 & 5 \\
\hline
\end{tabular}

(*) Excludes the intervals spent watching the movie

\section{Analysis}

To examine the rationality with which participants relate to the (hypothesized) norm that the teacher is responsible to sanction a statement as theorem in order to consider it installed, we inspected the corpus described above using a layered approach. A first inspection consisted of looking through the 125 intervals for intervals that contained discussions of the potential connection of the first problem (or its result) in the doing of the second problem. In a second inspection we looked into the intervals produced by the first inspection and determined the extent to which those conversations had considered the hypothesis or its negation. Finally, in a third inspection we looked 
into intervals where the hypothesis or its negation had been considered and extracted the ways in which participants perceived what had been done and what was missing in what the teacher did in the story, and how they appraised those actions.

\section{Identifying a Subcorpus of Intervals for the Hypothesized Norm}

To study the hypothesis that teachers are expected to sanction a proposition as theorem before holding students accountable to use the proposition as known in new problems, we restricted the corpus to those intervals that featured discussion about the connection between the first and second problems attempted by the geometry class shown in the animation. Of those 125 intervals potentially dedicated to discussing the story, 63 were identified as part of the sanctioning subcorpus in that they contained participants' discussion of the connection between the first problem and the second problem. This identification had a rater reliability of $100 \%$ over 15 intervals (Cohen's kappa $=1$ ). An example of a turn in an interval that contained that kind of discussion about the connection are:

Megan: Or even just add, what does this tell you about this triangle? What's a bonus thing that you get [Denise: Right.] from this proof? Or something like that. You need some kind of follow-up. Especially if you want to do that other problem. Cause that was sort of your whole point of having this in the homework is so that they'd get that theorem. (ITH-121505$17-694)^{11}$

Within these 63 intervals we found how many intervals contained evidence for the sanctioning hypothesis. The coding relies on noting the presence or absence of features in a complete interval.

We say that an interval contains evidence that the teacher is responsible to sanction a statement as theorem if the interval includes one or more participants' expectations that the teacher would directly sanction it (e.g., 'this is a theorem, use it') or indirect ones, such as those in which participants expected the teacher to initiate a sanctioning process (e.g., by asking 'what do

\footnotetext{
${ }^{11}$ The acronym and numbers refer to group (ITH or ESP) and session date, interval number, and turn.
} 
you think we have proved here that we could use later?'). We also included as evidence participants' expectations that the teacher would engage in such sanctioning immediately after Rho's proof of problem 33 as well as later, such as when discussing the solution to the problem of the day. The evidence in favor of the hypothesis can be found in repairs of the situation of installing the theorem, for example if someone denied that the base angles theorems had been installed because the teacher had not said that Rho had proved a theorem. Evidence could also be found in repairs of the tasks done within the situation (or how the situation had been carried out), for example by the participants indicating that the teacher had missed doing something or suggesting that something should have been done instead.

The key element of the hypothesis is the teacher's responsibility to sanction (or endorse; Sfard, 2007) the proposition as theorem, not the manner or the moment in which she should have done it. The negation of the hypothesis thus says that the teacher did not need to do anything extra, beyond having students realize that the statement is true, to be able to consider a statement as usable. In other words, if the hypothesis was not tenable, teachers would consider that the mere fact that the statement had been proved true was enough for students to know that they can use it in proving new propositions.

To formalize these coding operations, each interval was assigned a vector $(a, b)$ where $a$ and $b$ can be 0 or 1 . For an interval to have $a=1$ it meant that the interval contained evidence in support of the sanction hypothesis. For an interval to have $b=1$ it meant that the interval contained evidence that supported the negation of the sanction hypothesis. Clearly, considering that intervals are conversations among many individuals over possibly several minutes, both kinds of evidence could happen in an interval; that is, an interval could contain evidence for and against a hypothesis 
and thus be coded with the vector $(1,1)$. An example of this is interval ESP-011006-22, which contains the following two turns separated by a few minutes:

Megan: To me, until the teacher legitimizes that what that homework problem was... was a theorem, that's just a homework problem to them. (ESP-011006-22-400)

Esther: My kids ... would have said, "Well now we know that," they were, they would be much more likely to start using it right away. But you know, they're s-- some better students so... (ESP-011006-22-423)

It was also possible that an interval would feature a discussion of the connection between the first and second problem in the movie, making reference neither to the fact that the first problem was a theorem since it had been proven nor to the absence of sanction. The 63 intervals that did contain discussions of the connection between the first and second problem were coded according to the rules described above. These operations had a rater reliability of 90\% each; Cohen's kappa were 0.62 for $a$ and 0.74 for $b$. Table 2 shows the results of such coding.

The table shows that in 51 out of 63 intervals, that is, in $81 \%$ of the intervals of this subcorpus, the conversation among participants remarked on the absence of the teacher's sanction of the proposition proved by Rho. In contrast only 19 out of the same 63 intervals, that is in $30 \%$ of the intervals of this corpus, participants spoke of the proposition taking for granted that it was a theorem that could be used without further ado. This descriptive data adds credence to our hypothesis - the installation of a theorem seems to normatively require the teacher to mark a proposition as usable. Table 2 also shows how the numbers break down by group of practitionersthere were more intervals in the ITH group sessions discussing the connection between the two problems than in the ESP sessions. Yet the extent to which both groups dwelled more on the lack of sanctioning than on the lack of need for sanctioning seems rather similar across the two groups. 


\begin{tabular}{|c|c|c|c|}
\hline Table 2. & & & \\
\hline & $\begin{array}{c}\text { Intervals where } \\
\text { connection between } \\
\text { problems was discussed }\end{array}$ & $\begin{array}{c}\text { Intervals where evidence } \\
\text { for the hypothesis was } \\
\text { found }(\mathrm{a}=1)\end{array}$ & $\begin{array}{l}\text { Intervals where evidence } \\
\text { against the hypothesis } \\
\text { was found }(b=1)\end{array}$ \\
\hline ESP Sessions & 23 & 20 & 7 \\
\hline ITH Sessions & 40 & 31 & 12 \\
\hline All Sessions & 63 & 51 & 19 \\
\hline
\end{tabular}

What do these numbers mean? The ratios 31:66 and 20:59 (66 and 59 are the total number of intervals featuring conversations about this story in each of the groups; there were 125 across the sessions) estimate how much each of the groups brought up the sanctioning norm to their conversations about this animation. These numbers help document that their perception of the lack of sanction by the teacher was not an isolated occurrence over the length of the meetings but a rather salient theme. The ratios 20:23 and 31:40 estimate how often the conversations in each group were such that practitioners acknowledged responsibility to sanction a proposition as theorem in order to have it installed, in comparison to the number of conversations where that theme could have emerged (because they were already talking about the connection between the problems). The ratios 7:23 and 12:40 how often the conversations in each group were such that practitioners expressed that having proved the proposition was enough to have it installed, in comparison to the number of conversations where that theme could have emerged (because they were talking about the connection between the two problems). The comparison between those ratios for each group, namely $20: 23>7: 23$ on the one hand and 31:40 $>12: 40$ on the other hand gauge the extent to which each of these two groups considered the norm to sanction more important than the lack of need to sanction. Those ratios and comparisons document the salience of the hypothesized norm in comparison with its negation.

We take those numbers to mean that to the extent that these groups of practitioners represent the professional practice of geometry teachers, this practice is one such that the teacher is 
accountable for sanctioning a theorem. We don't interpret those numbers to mean that most or any of the participants in the conversations actually acts according to the norm most of the time, and not even that they personally believe such norm is appropriate. To assess the extent to which these groups really represent what the norms of the professional practice are, a larger sample of groups would be needed. Our confirmation that the sanctioning norm has a hold on what these practitioners consider a teacher to be responsible for is valuable insofar as it provides the needed background for the third layer of the analysis. It helps support our contention that reactions to the presumption that the teacher had installed the base angles theorem were not located in isolated conversations, but a rather common occurrence. Again, as a whole, the coded data shows that out of 125 conversations about this animation, 51 included a discussion of the responsibility to sanction. Thus, the second layer of analysis demonstrates the importance that these groups of practitioners allocated to the norm and thus recommends engaging a third layer of analysis in which we draw on particulars from the various conversations to account for the practical rationality available to handle the norm.

\section{An Examination of How Participants Perceived and Appreciated}

\section{the Actions in the Animated Story and the Alternatives They Proposed}

In this section we account for the themes that the groups of participants brought up in their reactions to the animated story, specifically in those intervals where they spoke of the connection between the first and second problems. As a first foray into exploring the practical rationality with which teachers of geometry relate to the sanctioning norm, we account for the different ways in which participants perceived and appreciated the story that they confronted-how they saw it, what alternatives for action that they saw in it, and what they adduced as reasons for those.

We presented the animation to the participants as showing an introduction of the base angles theorem. Yet, the animated story had been constructed so that the animated teacher did not 
explicitly label any segment of classroom activity. Thus it was possible that participants cast the story not as one of installing a theorem but as a story of something else, for example as instances of “doing proofs," (Herbst et al., 2009).

\section{Repairs of the Situation: What Is Really Going On?}

As a group, participants repaired the presumption that the teacher was installing a theorem by casting the story in at least four ways: as a story (1) of students coming up with a solution to a problem different than the one the teacher had thought of, (2) of students failing to make a connection between two proof problems, (3) of students employing the strategy used in one problem to solve another, and (4) where the teacher could have better helped connect two problems had he chosen mathematical objects differently. Figure 3 represents these different castings of the story all of which had in common that they repaired the situation: Rather than accepting the story as one about installing a theorem these repairs described it as instantiating a different situation, one of where what was at stake was students knowledge of how to do proofs. We discuss each of these in the following sections and come back to Figure 3 in the discussion.

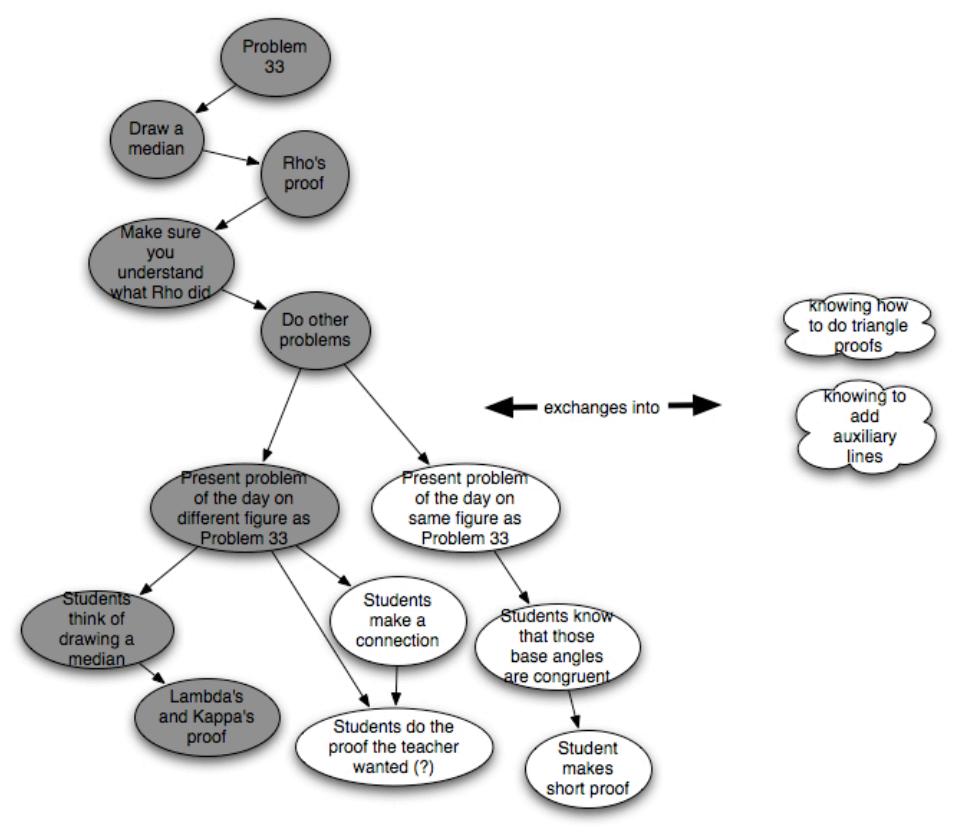


Figure 3. Possibilities of the isosceles triangle story if installing a theorem is not at stake.

'There is a shorter solution'. In some intervals, the conversation accounted for the story as if it involved only two problems. One of those interpretations was that these were just two problems, and that the animated teacher had a solution in mind for the second one that was different than what Lambda and Kappa had proposed. In interval ITH-121505-4 this was expressed thus:

397 Cynthia Well he said there was a shorter way to do that proof, and then didn't share it. Where some kids might have been confused with those [inaudible] and didn't go back and clear it up, just to make sure.

398 Moderator You're saying the teacher didn't clarify what--

399 Cynthia Yeah, well, he, he had just said that there was a shorter way, and maybe there was a more direct way to do that proof and just didn't go back and clear it up with some students. Cause maybe that, sometimes, I don't know, students go off on a tangent and they make the thing harder than it really is, even though they did it right, but. And he, he said that, um, but then didn't go back and just show them maybe a more direct way. [pause $2.5 \mathrm{sec}$ ] It's a problem.

400 Moderator S- so do you think there was a shorter way for them to do it? I mean, wh- what did the teacher //

401 Cynthia // He had said that there was.

It can be noted that the second problem in the movie is referred as a proof problem that could be solved in a "shorter way" or a "more direct way." But no reference is made to way in which the first problem influenced the posing or doing of the second problem. The conversation does not identify the teacher's frustration with the length of the proof as related to the students' lack of use of a piece of prior knowledge. No sympathy with the animated teacher's frustration is expressed. Instead, the students are absolved for not doing what the teacher expected on grounds that are related to students' general approach to doing problems - in particular, students are responsible for doing the second problem, but are not held accountable for knowing the base angles theorem. Instead the animated teacher is held accountable for showing what he was expecting. Thus, this rendering of the story accounts for the perception of different solutions for the same problem. An explicit category 
of appreciation that a short solution is preferable is confronted with a tacit category of appreciation that a student's own solution is preferable to someone else's (especially the teacher's) solution.

'These are two connected problems'. In some conversations, participants did expect students might make connections between one problem and the other. They were not necessarily articulate about what they expected students to do and not necessarily sympathetic with the animated teacher in his frustration. An important theme was "the connection" between those problems. The following excerpt from interval ITH-111605-18 exemplifies this rendering of the story:

229 Megan ... I think this whole video is sort of funny to me because it happens to me more in algebra, where the kids don't use a previous problem to help them. It's just extremely frustrating and I don't think this is really a geometry issue, this is a common kid issue.

230 Moderator So you think it won't happen, I mean, or it only happens in [...] class.

231 Megan No, it happens every day [laughs]. I'm saying it doesn't just happen in geometry. It probably happens more in my algebra classes.

232 Penelope Not, not making the connection.

233 Megan Yeah, they just did the problem and they don't see that the next problem is just like one more little extension of -- no, it's a totally new problem!

234 Penelope It's almost like you have to do an example for every problem that they're going to do on their homework or their assignment. They don't make the connection that okay, if I take it one step further then I might be able to solve this problem, you know. If you don't give an exact problem like that in your direct instruction they'll be like, oh you're trying to trick me or this or --

Thus the existence of a connection between the first and the second problem is acknowledged but perceived in very general terms: "us[ing] a previous problem to help [oneself]" (229) and "[a problem that did not come with an] exact problem like that in your direct instruction" (234). Unlike in the previous rendering of the story, in this one, sympathy with the animated teacher is expressed when observing that children will ordinarily fail to make those connections. But, in this interval, they show the object of their frustration as coarser in grain size than how a teacher would have to have perceived it if the teacher had deliberately constructed the two problems as a means to teach 
the base angles theorem. Thus, the story accounts for the perception of connected problems, one is perceived as an extension of the other. Two categories of appreciation are identifiable here, (1) that it would have been desirable for students to make a connection between the problems, and (2) that students don't usually make connections between problems.

'Students actually made a connection.' In at least one conversation, teachers were able to perceive and appreciate the proof provided by Lambda and Kappa in ways that the animated teacher had not. In their solution to the second problem Lambda and Kappa had used the same strategy used in the homework problem — to draw a median. In interval ESP-011006-26, this was noted thus:

494 Carl I think one of the most interesting things about this lesson was how they did actually take the hint from the first problem and apply it to the second problem. Just the more difficult the knowing hint. Like let's draw another altitude or whatever --

495 James Now we can drop lines down.

496 Carl Yeah, now, I mean that's great except you're working way too hard now. I mean, so maybe they're just using now the wrong half of the hint.

497 Moderator So should the teacher have given them a hint for the problem of the day?

498 Esther No. I liked it that they were having to think about what they still needed 499 Carl Yeah.

500 Esther -- and how they were gonna get there. I liked the discussion that they had where they said, "Oh we can get these sides but we, we need something else and we're not seeing where to get it," and so I think that was good that they had to think about what they should do.

The quoted conversation does show that participating teachers could perceive events at a grain size that looked into not just the existence of a connection between the problems but also the specific mathematics that the work in one task could afford the other. Thus, this rendering of the story also depicts the story as involving two connected problems, and an explicit connection between them is perceived: The same tactic (dropping an auxiliary line) is implemented in both. A category of appreciation identifiable here is that it is desirable for students to transform a diagram if they see it as advantageous. 
Making more apparent the connection between problems. Some conversations focused on what the animated teacher could have done to facilitate the making of a connection between the problems. In interval ITH-111605-24 two teachers discussed how they might have supported the students:

329 Tina They said they used it. But some kids wouldn't have made the connection from the first problem, problem 33, only the two sides are equal. This one actually said it was isosceles.

330 Denise So one of you would have, what if as a teacher you had went over to the first problem, the problem on the right, erased the median and drew the triangle inside. So you're using the same original triangle. Am I making sense with what I'm saying? And said, well let's try this. And used the same triangle, erased the median and drew the other triangle. Do you think they would follow?

331 Tina My students?

332 Denise Cause then they, yeah.

333 Res. Who would do that? You would do that?

334 Denise No, I'm just asking what if a teacher did that. Yeah, what if I was a teacher to do that.

335 Res. That would be clever.

336 Denise I mean would it make it better connected? [Pause.] Cause it seems like the problem is, the students, they did one problem and then they erased their brain and then they went on to another, which students do all the time, okay through with that problem, this is something totally different. You, know? [Laughs.]

In turn 330, the suggestion is made that instead of drawing a new triangle (on the left of the board) for the problem of the day, the teacher could have used the same diagram used by the first student (Rho). The teacher could have erased the median Rho had drawn and drawn instead the triangle formed by the midpoints of the sides. The goal of such moves would apparently be to "make it [the second problem] better connected [to the first]," (ITH-111605-24-336) so that students would not "erase [the one problem from] their brain and then [go] to another, which students do all the time" (ITH-111605-24-336). We note that such a solution to the pedagogical issue would indeed keep a close connection between the two problems as related to the same triangle. We note that in that case the solution of the second problem would clearly make use of the fact proved earlier about that triangle (that base angles are equal in that triangle) but it would not clearly make use of the result 
valid for all triangles, also produced by the first problem. We thus take these conversations as containing repairs of the situation: What was perceived to be at stake in the story was the doing of two proof problems which were connected by the possibility that both could be posed in the same triangle; and, in that case, the fact proved by one problem could be useful information for the doing of the second problem. What was missed, or perhaps downplayed, in that rendering of the story is, of course, the general result proved in the first problem, that any time two sides in a triangle are congruent their opposite angles would be congruent as well. Thus, in this rendering of the story, we note as categories of perception the specific objects on which the problems are posed (how mathematical objects are represented through description and notation). As categories of appreciation we note that (1) students are likelier to make connections between problems if they are posed in relation to the same mathematical object and (2) that enhancing the likelihood of their making of such connections by posing the problems in relation to the same object is more desirable for the teacher than expecting students to make connections across objects on their own.

\section{Repairs of the Task: "He Is Trying to Get Them to Use the Theorem"}

While the interpretations of the story provided above repaired the presumption that a theorem had been at stake, other renderings of the story accepted this presumption and, instead, repaired the specific tasks that the teacher, or the students, had to do to fulfill the installation of the theorem. In these renderings of the story, we encountered repairs to how students had respondedincluding (1) rendering the story as one where a theorem had indeed been proved for homework, (2) a rendering that cast all proof problems done by students as theorems of some sort, and (3) a rendering that questioned the likelihood of the event that no student be able to connect the result proved in the first problem to the second problem. We also found renderings of the story that repaired what the teacher had done or failed to do, including the indications that the teacher missed 
(4) labeling the exercise as one of proving a theorem, (5) asking students to state conceptually what they had proved, (6) labeling the result proved in a way that could be referred later, and (7) introducing the first result as theorem later, on account of its usefulness to do the second problem. Figure 4 represents these different castings of the story all of which had in common that they accepted the situation as one about installing the base angles theorem and repaired one or more of the tasks of the teacher or the student. We discuss each of these in the following sections and come back to Figure 4 in the discussion section.

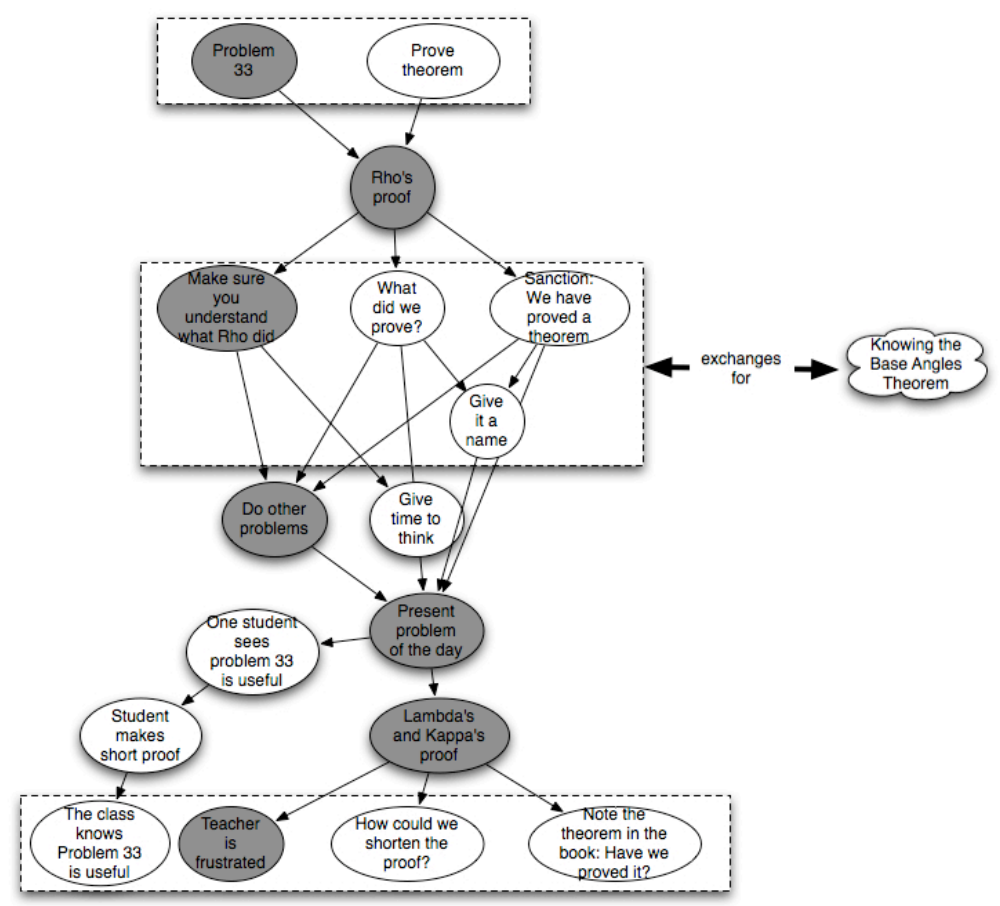

Figure 4. Possibilities of the isosceles triangle story if installing a theorem is at stake.

A theorem was proved for homework. In most of the intervals where participants talked about the connection between first and second problem, they recognized that the intent of the teacher in giving the second problem had been to enable students to use the result proved in the first problem. For example, right after watching the teacher pose the second problem, we heard that the animated teacher's expectation was that students: 
Use that theorem that she just proved and then get side angle side right away. Three steps. (ITH-111605-18-227)

Likewise, on the following month's meeting of the same group, and in response to the observation that the teacher was not happy with the way students had done the second problem, we heard

He's trying to get them to use the theorem that was proved in the homework. That if you have two equal sides then the base angles are equal. If they'd used that they wouldn't have had to prove the triangles were equal. That would wipe out three steps in their proof. (ITH121505-4-403)

Even though in the animation the first problem is not referred to as a theorem, the utterances above identify it as a theorem and note that, if that theorem were used, the solution to the second proof problem would be shorter. In these conversations, the theorem and the teacher's intention to install it were perceived. We note here not only that the problem proved by Rho was perceived as the proof of a theorem (rather than just a proof problem), but also that this proof was perceived as proving a general statement (stated in terms of concepts such as equal sides and base angles). As categories of appreciation here, we note that it is desirable to shorten proofs by using known theorems.

'You always have one student who can say those things.' In some conversations, participants saw the intent of the teacher to enable students to use the theorem, and were baffled at the lack of positive response on the part of students. In interval ESP-011006-51, we heard

1082 Esther Uh...I have a lot kids that are looking for a shortcut. I think there probably would have been at least some kid in the class, because my class isn't that small.

1083 Carl Somebody would have. Somebody would have noticed the shortcut.

1084 Esther I think somebody would have said, "Well...you didn't have to draw that in." I think some kid would have said that.

1085 Carl And maybe that's my -- Maybe that's the big criticism, is that... Everybody's too clueless in this, in this thing, y'know? The students are really too -- there's nobody in the class that's really saying -because you always have someone in the class.

1086 Esther Somebody would say, "Well I don't need to draw it in because we did it," I think somebody would have said that.

1087 Carl Somebody would have said that.

1088 Res. And the teacher would, would move to hearing that person who had 
the idea?

1089 Megan The de-- this guy definitely would. He's dying up there.

1090 [laughter]

Thus, participants realized that it would have been on the students' best interest to use the result proved (it was a shortcut), and expected that at least one student should have seen the connection. That is, they could see how noticing the usefulness of the result proved could come from the floor, through at least one student, and how that student could spread the message to the whole class. It was frustrating and unrealistic in their view that no student in the animation had done that. Participants suggested that other opinions could have been solicited to make room for that contribution. Participants made comments that repaired the way the solution to the second problem was managed tactically, indicating, among other things, that a solution that used the result proved in the first problem could have been offered had the teacher continued to prod other students to share other possible ways of solving the problem—-with questions such as "can anybody think of another way, or a shorter [way]?” (ESP 010006-71-1136).

We thus note in this rendering of the story a category of perception that singles out a particular kind of student, the student who is able to note and speak up about connections that are not apparent to the majority of geometry students. We note also two categories of appreciation related to that category of students: (1) that it would be usual for a geometry class to have at least one student with those characteristics, and (2) that it would be appropriate for a teacher to count on that student's noticing of the import on the second proof of the result proved on the first problem. We also note as a category of appreciation (3) that the emergence of a reference to the first problem would have benefited from the teacher's prod to give other, shorter solutions to the second problem. 'But to them it was just a proof problem.' We had hypothesized that the work the teacher needs to do to install a theorem includes sanctioning a proposition as theorem. If our hypothesis was tenable 
and participants acknowledged the teacher's expectation that students use the result proved in the first problem as if it were a theorem, we predicted participants would react to the lack of sanctioning by the teacher in the story. This reaction was manifest by way of repairs such as:

Right. So they haven't proved that, they haven't technically proved that theorem yet, even though they did the problem proving it, he hasn't stated it as a theorem yet. Do you see what I'm saying? (ITH-111605-19-255)

Later on that same session, in interval ITH-111605-21, participants picked up on that theme

292 Edwin Yeah. They haven't made it official yet, it was a problem in the book. It wasn't a theorem you know, even though they proved it, it's not--

293 Tina They don't look at it as a theorem yet.

The distinction between a problem in the book and a theorem pointed to the lack of sanctioning. In another conversation, it was noted that students' work could have turned out to be different had the task statement been different:

If the problem in the book had said, "Prove theorem," and then said "base angles of an isosceles triangles are congruent" and then the kid did this exact problem on the board everybody woulda used it on the other problem. (ESP-011006-38-793)

And also,

Once you come up with something like earth-shattering like the [...] like the base angles of a triangle, of an isosceles triangle are congruent, you have to do a song and dance or else it's not gonna get into their toolbox, y'know. (ESP-011006-23-440)

Thus, sanctioning mattered. It mattered, in particular, as regards to clarifying for students what was at stake in the work being done. Participants perceived a difference between the bare statement of a proof problem and the same statement being sanctioned as a theorem. The categories of appreciation we observed here include that it would be usual for students to think of a proof problem as only that unless it was also identified as a theorem.

Anything they prove could be a theorem. In contrast with the notion that, for students, all they had done was a proof exercise, we heard 
That's sort of interesting because every time they do a proof in their book it is, it could be a theorem. (ITH-111605-21-295)

And again later in the same interval

299 Megan I never thought of it before, but it's true. Every single little homework problem that they prove something, granted it's a theorem specific for that little diagram, but --

300 Edwin Right.

Thus, one of the ways in which the proposition proved could be perceived is as a theorem, because it had been proved. Yet the qualification is meaningful: "a theorem specific for that little diagram." This could be contrasted with the comment, noted in the previous section, that if the exercise had said to "prove a theorem" students would have used it —in this comment the theorem is described as a theorem that applies to the set of figures described by the concept "isosceles triangles." Thus, participants repaired the task by bringing to question what the proposition was, but were accepting of the possibility that students could be the ones proving a theorem. We note here as a category of perception what a theorem is (for participants): anything that students proved could be considered a theorem, because it has been proved. As a category of appreciation we identify, in this rendering of the story, that it is usual for students to prove what could be considered theorems specific to a figure.

'So what did we just prove?' The participants in our sessions were attuned to the fact that the proposition proved by Rho looked different than how the statements of theorems ordinarily look. They proposed that the teacher could have helped turn Rho's proof into the installation of a theorem. In interval ESP-011006-38, they spoke thus

807 Megan Oh that's true. If it said that in words instead of just having the symbols, 'cause this particular problem just said prove angle B equals angle $\mathrm{C}$ and didn't say you have an isosc--that's true, I bet you're right. I bet if it had said it in words like as a statement it would have been more legitimized too. Because that's how they're written out usually. Not written out like this. 
808 Moderator So you're saying even if it hadn't been called a theorem, if it had been said in words people would have been more likely to use it.

809 Megan Yeah, they said "prove the base angles -- use this diagram to prove the base angles of an isosceles triangle are congruent." You're right. Yeah I think you're right.

810 James Yeah that's a good point too because one of the things I was gonna say about when they went to the next exercise, a lot of times when students are looking at this triangle $\mathrm{ABC}$, even if you draw another triangle $\mathrm{ABC}$ they've kind of been, uh, trained that that's a different triangle and so that angle $\mathrm{B}$ and that angle $\mathrm{C}$ and that $\mathrm{AB}$ and that $\mathrm{AC}$ don't necessarily have to be congruent in the new triangle, y'know, so, so if you aren't given that then you know it's a different triangle so it kind of segregates out the two things. They - y'know I could see then because of that where they wouldn't relate "oh yeah, we did triangle ABC," but that's not the triangle we're working (on there.)

Later in that session the participants discussed whether having students translate the specific result proved into a conceptual register (Weiss \& Herbst, 2007) would enhance their chances to use it. In that context the following conversation ensued in interval ESP-011006-68:

868 Karen "So what did we just prove?" kind of thing. I, yeah I like it.

869 Megan But you can't do it all the time. You'd have to look through the assignment and say, [Esther: Yeah...] problem number 6 and 10 I want you to, when you finish it, write in your own words what you think you proved. Because some of them like [the moderator is] saying are...

870 Esther Not going to be productive.

871 Megan Yeah.

872 Res. So some exercises, you wouldn't come up with a nice statement.

873 Megan Right. No.

874 Res. And why, so you're saying it wouldn't be worth actually going through the exercise of trying to say what you did? Wha-- say in words?

875 Esther Well because the conditions are so specific, I think is what we're saying. It had to be such a specific set of circumstances that it doesn't -- it's not really a good generalizing situation. I think is what, I think that's what we meant...

876 Res. OK. And you're saying many of the proof exercises aren't.

877 Esther Well sometim_yeah, well some of them are like that, yeah.

Participants also indicated that the location of and attention given to problem 33 could have been different. In interval ITH-111605-46 it was suggested that, since homework problem 33 contained important material for the day's work, it should have been left to the end of homework review, so as 
to bring it closer to the problem of the day. Also participants noted that more time would have been needed to reflect on problem 33, suggesting questions such as "Does everybody realize what we did up there?” (ITH-111605-46-641). That would have been preferable to how the animated teacher actually handled it (merely saying "make sure you understand what Rho has done there"). So, while proof problem number 33 was, in this case, one that could be translated into a property of all isosceles triangles, the participants were not confident that the same should, or could, be done about any proof problem. In many cases, the specificity of the conclusion proved might make it not generalizable into a useful result. In this rendering of the story we note, as a category of perception, the possibility to translate some proof problems into conceptual propositions. We note also as categories of appreciation that (1) it would have been appropriate for the animated teacher to prompt students to translate what they had proved into a conceptual statement, (2) for many of the proofs that students ordinarily do, such translation would not be productive, (3) it would have been appropriate to locate the first problem closer to the second problem so as to make its relevance more apparent, and (4) it would have been appropriate to better support students' attention to what had been proved in the first problem by giving time for reflection as well as appropriate questions.

'What did you expect they put in there: Problem 33?' Another repair of the tasks done while installing the base angles theorem consisted of noticing that the lack of a name to use in referring to the result proved conspired against its usability. Hence, in interval ITH-111605-21:

284 Res. Why do [you] think students [would not] use it. The teacher expected them to use it.

285 Tina Because we haven't said it's so.

286 Edwin We haven't given it a name, haven't made it official.

And later in interval ITH-111605-36

540 Res. So you would expect that they would make that connection instead of reproducing the same proof.

541 Tina If they didn't and they reproduced it I would've done it different than 
him and I would have written a whole big long proof up on the board if they did. And then what I would have done is, ok these 4 steps, notice they're the same as the problem we did over here, we could have condensed this all down and just said this because of problem 33. 542 Megan And then, but kids aren't used to writing that as using proofs. 543 Tina Right.

Thus we noted in these conversations as a category of perception how elements of knowledge are labeled and as a category of appreciation the notion that if the proved statement had had a name this would have likely enabled students' use of it in the second proof.

It could have been sanctioned later. As noted above, it was a relatively common occurrence that participants found fault with the animated teacher for not having sanctioned the theorem once proved. However, they also valued the animated teacher's strategy of giving students the opportunity to notice and use the result before sanctioning it. A compromise position was articulated apropos of the discussion of how the animated teacher handled students' approaches to the second problem. The following conversation happened in interval ITH-111605-54:

718 Animation ["We knew that it would have to be true, but we had to prove it." Animation stops.]

719 Tina So right there he should have said it.

720 Denise And after that he just goes on.

721 Moderator And you're saying he should have stopped there?

722 Denise Right, isn't that the main point of it? He should have stopped and said well how did you know it? Because they, he said, "Well sort of, we knew it, we just have to prove it."

723 Tina Well then why didn't he call on Rho right then? Wasn't it Rho? Rho who did the first problem? And say, "Rho, how would they?" you know.

724 Denise Right.

725 Moderator So you're saying that --

726 Tina He missed the opportunity.

That is, participants identified the discussion of the second problem not only as a chance to verify whether or not students were able to reuse what they had proved, but also as a place where the teacher could have exercised his duty to sanction the theorem. The second problem gave a context 
for showing the usefulness of having the first result as a theorem, since having this result as a theorem could help reduce the number of steps in the proof of the second problem. Participants recommended that the proof of the second problem could have been written down in detail and then compared side by side with the proof for the first problem, so as to impress upon the students that the first statement proved was useful to shorten the second proof. Participants also noted that, while doing the second problem, some students in the animation had found the theorem statement in the book: Participants recommended that at that point in time the teacher could have connected it with the first problem, indicating that they could use the theorem because it had already been proved.

Thus, participants could see value in delaying the sanctioning of the proposition, and did not necessarily expect that the teacher sanctioned the proposition just as soon as the proof was done. As a category of perception, we observe here participants' attunement to the timing of the sanction of a theorem and to the possibility to justify why a statement should be considered a theorem. As categories of appreciation we note that (1) it would be desirable to give students the chance to use the proved result in the second problem, (2) students might need the teacher's prompt to look for similarities between the two proofs, (3) it would be appropriate for the teacher to note that because of its relevance in solving other problems that first result should be a theorem, and (4) students might need the teacher to note similarities between the statement proved and the theorem in the book.

\section{Discussion: The Practical Rationality}

with which Teachers Handle the Installation of Theorems

The previous section has shown how our thought experiments can allow us to do two things. On the one hand, from the existence of reactions to the animated teacher's goal, actions, and eventual frustration we confirm that, to the extent that these small groups of participants represent 
teachers of high school geometry as a group, practitioners recognize that a teacher is expected to sanction a proposition as theorem if students will be expected to use it. Teachers recognize that as a norm, which is apparent in expressions like "there needs to be a discovery entrance or something" (ITH-111605-21-290) or "when you discover something earth shattering, you have to do a song and dance" (ESP-011006-23-440). On the other hand, the thought experiments elicit from practitioners data that sheds light on their practical rationality. This comes in the form of categories of perception and appreciation that participants utilize in talk as they construct their reactions to the animationparticularly in rendering the story watched and in appraising moments in the story watched, or in conceivable alternatives. We dedicate most of this section to synthesize what we have learned about this rationality through the use of the animated story "Isosceles triangles: A Homework Problem."

The existence of a norm in an instructional situation does not mean an individual teacher would necessarily act according to it. In the case examined, the norm for a teacher to sanction a result as theorem means that teachers may default to sanction a result as theorem, if they want to hold students accountable to use it. Yet, the data shows that scenarios like the one depicted in the animation could be viable, albeit with some modifications.

A first set of reactions was classed under the heading "Repairs of the situation" and consist of the different ways in which practitioners countered the notion that what was at stake in the episode was the installation of a theorem. Instead they rendered the episode as one of doing proof problems or as one of demonstrating knowledge of a proof tactic. The diagram in Figure 3 accounts for this set of renderings of the story, showing what kind of work could be done and the exchange values that this work could have.

In narrating (or creating alternatives to) the episode in those ways practitioners demonstrated their perception attuned to the following categories: 
- Problems: Two problems can be connected in different ways such as when one extends on the other or when one uses the same tactic as the other.

- Solutions to problems: Students can produce solutions to a problem that are different than what the teacher expects.

- Mathematical objects and their representation: The same mathematical object may be referred to with different descriptions or notations.

In arguing for the various moves in these set of stories, participants called forth the following categories of appreciation, which enabled appraisals on the courses of action listed in Figure 3:

- Length of solution: A short solution to a problem is preferable to a long solution.

- Authorship of solution: A student's own solution is preferable to someone else's (the teacher's) solution.

- Using prior work: It is desirable for students to use the solution of a problem in solving another problem.

- Making connections: Students usually don't make connections between problems. Students are more likely to make connections between problems if they are posed in relation to the same mathematical object.

- Modifying a diagram: It is desirable for students to add an auxiliary line if this is needed for solving a problem.

In other reactions to the animation, participants were amenable to the idea that through giving these two problems the teacher meant to install the base angles theorem. Figure 4 shows the various renderings of the story that according to participants were aimed at this goal, showing what kind of work could have been done and the exchange values it could have had. The dotted boxes around clusters of possible moves identify moments when one option was to sanction the proposition (to be) proved as a theorem. In narrating (or creating alternatives to) the episode in those ways practitioners demonstrated their perception attuned to the following categories (sample):

- Statements: The statement proved in a proof problem can be interpreted as a general statement.

- Theorem: Theorems are propositions that are useful to prove other things

- Proofs: A proof problem can also be the proof of a theorem

- Students: There are geometry students who are able to note, and speak up about, connections that are not apparent to the majority of other students.

- Timing: A proposition might be sanctioned as theorem when the proposition is deemed useful 
In arguing for the various moves in these set of stories, participants called forth categories of appreciation including the following (which warranted the courses of action listed in Figure 4).

- Theorems shorten proofs: It is desirable to shorten proofs by using known theorems instead of proving anew properties that could be inferred.

- Students who make connections exist: It is usual for a geometry class to have at least one student who can make and speak up about connections that others don't make.

- Proof problems are just that: Students are likely to think of a proof problem as merely a proof problem if it is not identified as a theorem.

- Conceptual propositions: It would be appropriate for a teacher to prompt students to translate what they have proved in a proof exercise into a conceptual proposition.

- Named or labeled statements: If a proved statement were labeled or named, students would be likely to use it later.

- Useful statements are theorems: It would be appropriate for the teacher to note that because of its relevance in solving other problems a proved result should be a theorem.

- Theorems and the statement proved: Students might need the teacher to note similarities between the statement proved and the theorem in the book.

- Problem relevance: It would have been appropriate to locate the first problem closer to the second problem so as to make its relevance more apparent.

Among other things, the data shows that while ordinarily a teacher would be expected to sanction a proved proposition as a theorem if he or she expected students to use it, it is quite possible for a teacher to create conditions for students to use a proposition they have proved, without directly telling them to do so. Our data shows that a number of resources are available for a teacher to support students in recognizing the usefulness of the proposition proved. These include prompting them to restate the result proved in general terms, prompting students to consider whether the proof of the new problem could be shortened, and promoting thinking and discussion of the import of what had been proved. In interval ITH-111605-69, we heard that students could be asked

897 Denise Can we make a conjecture from problem 33? Let's look at problem 33 and everybody come up with a conjecture. And then I'll have people tell me what their conjectures are. I bet you 9 times out of 10 someone's gonna say an isosceles triangle has two congruent base angles. Cause that's what problem 33 is, and then you could say well that's what I've been trying to tell you guys that's our next theorem. And then they came up with that on their own still. 
The importance of these findings about how practical rationality can support geometry teachers handling of the situation of installing a theorem can be argued on account of policy pushes on instruction that might possibly create a tension for a teacher. On the one hand, teachers are expected to engage students with the ideas and practices of a discipline. This could mean that students' opportunity to learn should include target propositions that the discipline treasures as theorems and that students should have the opportunity to learn the role that theorems play as targets of mathematical investigation and capsules of mathematical knowledge. On the other hand, teachers are expected to engage students as active participants of mathematical inquiry. This could mean that studying should not just involve acquiring information about those theorems that mathematicians have targeted in the past, but actually pursuing them as targets of students' own mathematical work. A teacher is expected to aim at both sound disciplinary knowledge and active construction by students. That kind of instruction may be desirable, but one needs to ask whether and how such kind of instruction is feasible from the perspective of the practitioner and how a practitioner can manage the tensions that come along with making it happen. We believe the results of this study provide some pointers that can inform that question.

The particular story we used to spur conversation among geometry teachers displayed a rather modest attempt on the part of a teacher to allocate agency to students in installing a theorem. Students were given the opportunity to avail themselves of a prior result to produce a new result. The way the prior result had been encountered and recorded made it already mathematically correct — the opportunity for students seemed to include little risk for the teacher. Still, our participants found that management risky and in their comments they elaborated on those risks.

A main risk is that of losing control of the boundaries between the statements that students prove when they "do proofs" and the theorems that the class needs to record as valuable knowledge. 
We contend that the sanctioning norm describes a customary practice that exists to protect those boundaries. The practical rationality of mathematics teaching contains resources that support the desirability to challenge such norm — note above categories of appreciation that put a premium on students' making connections. But the prospect of success depends on more than the will of the teacher to challenge custom. Whereas all proof exercises might be stated as true propositions, if anything that could be proved received the status of theorem, that might not only create a misrepresentation of disciplinary knowledge (where not all true propositions are theorems) but it would also tax the capacity of the class (and of the teacher) to remember what is publicly known. Conversely, if nothing in the students' activity was differentiated as more important than the rest, the activity might not increase students' awareness of their increased knowledge of mathematics. It is understandable, therefore, why the norm is that the teacher sanctions theorems even if students might be fully able (and enabled) to conjecture and prove them. It seems plausible that instructional activities that protect a role for (and support the work of) the teacher in negotiating whether a statement can be a theorem would fare better than instructional activities that implicate the teacher in tacitly canonizing any conjecture made and proved by students, or than activities that prevent the teacher from any such sanctioning (see Chazan and Houde, 1989).

A potential risk of a teacher's reluctance to sanction a theorem was anticipated in the section titled “Making more apparent the connection between problems.” An inflexible position against sanctioning, but seeking student success, might lead to reducing the identification and reinvestment of prior knowledge (the use of a theorem) to the mere making of connections across problems. A teacher who renounces the responsibility to sanction might otherwise work to increase the chances that students make some connection by juxtaposing in time tasks that enlist the same operations, or by cueing such recognition through the reinvestment of the same representations in subsequent 
problems (reminiscent of some teaching of computational methods). Connections made in this way may appear more actively made by students, but their value as mathematical practices would be more questionable. In particular, they could turn legitimate mathematical activity into activity that does not generate knowledge as value added.

The data seem to suggest that organizing tasks in such a way that students can recognize a previously proved proposition as useful, and can reuse it in solving a new problem more efficiently, may be desirable from the perspective of geometry teachers. Supports to make such activity feasible should include ways for the teacher to monitor the mathematical qualities of the connections made, and ways for the teacher to maintain students' work within boundaries that permit it to be cashable or exchangeable for claims to useful knowledge. One of these supports can come in the form of providing an explicit, metamathematical or metadiscursive, definition of theorem as part of the curriculum, a definition that sets expectations for a proposition to be a theorem (or property) to the extent that such proposition is important, useful as a tool to find out other things (as much as it is a result by itself). Another support could include making room for the custom of translating the propositions students prove as exercises into the conceptual register, routinely asking questions like "How would you state what you proved in words?" or even "Would the proof you wrote be true for any isosceles triangle?" In general, it seems as though students' capacity to consider what they prove as potentially useful, and thus memorable, hinges on developing means to turn the claims they prove (rather than just the proofs themselves) into objects of reflection.

\section{Conclusion: About Constructs and Methods Used in this Study}

In this study, we have illustrated a new way to study the rationality that undergirds the activity of teaching. While observation and ethnography of the wisdom of practice (Shulman, 2000) provide initial means for discovery of what is involved in the work of teaching, our theory and 
methods contribute ways of making and probing hypotheses about the practical rationality of mathematics teachers. Specifically, the notion of instructional situation (e.g., "installing a theorem") specifies the object of study, the notion of norm (e.g., the "sanctioning" norm) helps model that object of study, and the notion of a thought experiment that uses a prototype of such a model helps elicit data that inform the object of study. The notion of practical rationality gives a name to the data so collected: The practice's ways and means of handling the demands of an instructional situation.

Practical rationality contains the categories of perception and appreciation with which teachers relate to the demands of an instructional situation. Thus, different categories may be used to handle different situations. This was particularly visible in the data when one contrasts the categories of perception and appreciation brought up to reject the presumption that the animated teacher was installing a theorem and those brought up to repair the way in which the teacher went about installing a theorem. Thus, we conjecture that practitioners may differently perceive and value objects and actions depending on the instructional situation where they are working. If this conjecture is plausible, the notion of practical rationality may be useful in enabling the field to move the discussion of teachers' thinking about teaching beyond the study of broad teacher beliefs and deeper into the study of decision making in specific instructional situations.

Obviously, it is possible that the empirical study of practical rationality in different situations (e.g., "installing theorems" and "doing proofs") might yield as a result that some elements of practical rationality are common across instructional situations. These might be attributable to the practical rationality with which practitioners handle general demands of the didactical contract for a particular course (e.g., high school geometry). Further, it is possible that in eliciting practical rationality for situations in geometry as well as in algebra, we might find evidence that some elements of practical rationality recur across courses of study and propose that the ways in which 
practitioners differently handle the whole didactical contract for mathematics instruction rely on some common elements of practical rationality. We consider it premature to make those kinds of claims and suggest that if our technique can be used in other inquiries, researchers need to start from modeling a particular instructional situation. The paper shows how such study of teaching can be conducted, by starting from a hypothesis about what is normative in a situation, designing a representation that probes such norm, and obtaining from practitioners data that accounts for the categories of perception and value with which they handle such norm and explain its presence.

We suggest that our data collection technique has been particularly helpful to elicit these categories of perception and appreciation from practitioners. Our classroom observations would have enabled us to create a survey instrument in which we asked practitioners whether they perceived a teacher to be under expectations such as sanctioning a theorem or whether they would consider it appropriate to let students figure out on their own that they can use a proved result. But, in turning that tacit norm and its alternative (or breach) into explicit statements, something about the nature of the phenomenon would have been taken for granted: The extent to which it is an issue for teachers whether they sanction a theorem or not. By using scenarios as prompts for teachers to comment on, our technique does not make the assumption that norms like that one are explicit.

Our data collection technique has been particularly helpful also in eliciting practitioners' rationality apropos of specific clusters of practices in geometry classrooms, which we call instructional situations. Clearly, video records could have been used for similar purposes, as others' and our earlier work shows (Herbst \& Chazan, 2003; Jacobs \& Morita, 2002; Nachlieli \& Herbst, 2009; Weiss, Herbst, \& Chen, 2009). Video records may however call too much attention to the individuality of people and settings away from the practice whose norms we are interested in exploring. But by using non-descript cartoon characters we have been able to focus participant 
reactions on pedagogical and mathematical aspects of practice rather than on the individualities of people and settings (Herbst et al., in press). We are fully aware that human action is not just a response to the demands of a practice (in particular, a situation); action also is expression of individuality and an adaptation to context. But while it seems to us that those aspects of action are well taken care of by disciplines such as psychology and sociology, the need to understand the specifics of instructional practice in mathematics require its own theories and methods. While we reduce some complexity (particularly individual differences and social context), we are able to bring in quite a bit of instructional complexity through the use of our technique.

Finally our technique of using these representations of teaching with groups of teachers has served us well to inventory the content of practical rationality as it concerns the work of installing a theorem. Clearly we could have used these representations to broker individual interviews and that would have been advisable if we had been after a different research goal. The work with homogeneous groups of practitioners has allowed us to get at two things that might have been harder to get to in individual interviews. On the one hand, by having to respond to the animations in front of their colleagues, practitioners could not stray too far from informing about the norm without having to qualify their comments. This enabled us to inventory, as viable responses to the norm, courses of action that reflected more the rationality of the practice than that of the individual practitioners. On the other hand, by being able to participate in conversations about practice with their colleagues rather than being the sole speakers, individual teachers had more encouragement and support to contribute to inventorying the rationality of practice. Some times individuals contributed merely by "chiming in;" other times it was apparent that their capacity to be critical of the instruction represented fed from the number of them and their agreement. In particular, participants were more likely to use their own categories of perception (and language) than if they 
had been responding to questions from an interviewer. Obviously if we were interested in issues of individual growth through these sessions, individual histories becoming socialized to the norms of practice, or individual knowledge handling those practices, other techniques for data collection or data analysis would be needed.

This paper does not investigate how individual teachers relate to the construct we call practical rationality. Thus far, in our conceptualization, practical rationality belongs to practice and practitioners are socialized to it (Waller, 1961). Instrumental in maintaining that interpretation of the data were the sampling decision to work with a group of experienced teachers of high school geometry and the design decision to engage them in collective thought experiments materialized as conversations. Thus, while individuals made the comments, they did so under the surveillance of their colleagues - what they said might have been what they personally believed or what they were expected to personally believe - for our purposes what mattered is that it could acceptably be said within a conversation among colleagues socialized into the practice of teaching geometry. Future research could investigate how individuals position and cluster within collectives as far as their socialization into the rationality of practice: Are there differentiable classes of practitioners that might embody substantial differences in practical rationality? Future research could also look into how individuals become socialized into the rationality of practice: Are there mechanisms that do that job and how do they work? Finally, future research could look into the relationships between individual knowledge and practical rationality: Can the presence and amount of particular kinds of teacher knowledge help explain the considerations that a practitioner make when handling the demands of an instructional situation?

\section{References}

Balacheff, N. (1991). Construction et anlyse d'une situation didactique. Le cas de 'la somme des angles d'un triangle'. Journal für Mathematik-Didaktik 12(2/3), 199-264. 
Balacheff, N. (1999). Contract and custom: Two registers of didactical interactions. The Mathematics Educator 9(2), 23-29.

Ball, D. L., and Bass, H. (2000). Making believe: The collective construction of public mathematical knowledge in the elementary classroom. In D. Phillips (Ed.), Yearbook of the National Society for the Study of Education, Constructivism in Education (pp. 193-224). Chicago: University of Chicago Press.

Ball, D., Lubienski, S., \& Mewborn, D. (2001). Research on teaching mathematics: The unsolved problem of teachers' mathematical knowledge. In V. Richardson (Ed.) Handbook of research on teaching (4th ed., pp. 433-456). New York: Macmillan.

Ball, D. L., Thames, M., and Phelps, G. (2008). Content knowledge for teaching: What makes it special? Journal of Teacher Education, 59(5), 389-407.

Bauersfeld, H. (1980). Hidden dimensions in the so-called reality of a mathematics classroom. Educational Studies in Mathematics, 11(1), 23-41

Boaler, J. (2002). Experiencing school mathematics: Traditional and reform approaches to teaching and their impact on student learning (Rev. and expanded ed.). Mahwah, NJ: Lawrence Erlbaum Associates, Inc.

Borko, H. and Shavelson, R. (1990). Teacher decision making. In B. F. Jones \& L. Idol (Eds.) Dimensions of thinking and cognitive instruction (pp. 311-346). London: Routledge.

Bourdieu, P. (1990). The logic of practice. Stanford, CA: Stanford University Press.

Bourdieu, P. (1998). Practical reason: On the theory of action. Palo Alto, CA: Stanford University Press.

Bourdieu, P. \& Wacquant, L. (1992). An invitation to reflexive sociology. Chicago: University of Chicago Press.

Brousseau, G. (1997). Theory of didactical situations in mathematics: Didactique des Mathematiques 1970-1990 (Balacheff, N., Cooper, M., Sutherland, R., \& Warfield, V., Eds. \& Trans.). Dordrecht, The Netherlands: Kluwer.

Buchmann, M. (1986). Role over person: Morality and authenticity in teaching. Teachers' College Record, 87(4), 529-543.

Chazan, D. and Ball, D. (1999). Beyond being told not to tell. For the Learning of Mathematics, 19(2), 2-10.

Chazan, D. and Herbst, P. (in review). Animations of classroom interaction: Expanding the boundaries of video records of practice. In review at Teachers' College Record.

Chazan D., \& Houde R. (1989) How to use conjecturing and microcomputers to teach geometry. Reston, VA: NCTM.

Chazan, D. and H. M. Lueke. (2009). Exploring tensions between disciplinary knowledge and school mathematics: Implications for reasoning the place of reasoning and proof in school mathematics. In D. Stylianou, M. Blanton \& E. Knuth (Eds.), Teaching and learning proof across the grades (pp. 21-39). New York, NY: Routledge.

Clandinin, D. J. and Connelly, F. M. (1996). Teachers' Professional Knowledge Landscapes: Teacher stories, stories of teachers, school stories, stories of schools. Educational Researcher, 
25(3), 24-30.

Cobb, P., Wood, T., Yackel, E., \& McNeal, G. (1992). Characteristics of classroom mathematics traditions: An interactional analysis. American Educational Research Journal, 29, 573-602.

Cohen, D. K. (1990). A revolution in one classroom: The case of Mrs. Oublier. Educational Evaluation and Policy Analysis, 12, 327-345.

Cohen, D. K. (2005). Professions of human improvement: Predicaments of teaching. In M. Nisan \& O Schremer (Eds.), Educational Deliberations. Jerusalem: Keter Publishers.

Cohen, D. K., Raudenbush, S., and Ball, D. L. (2003). Resources, instruction, and research. Educational Evaluation and Policy Analysis. 25, 119-142.

Cook, S. D., \& Brown, J. S. (1999). Bridging epistemologies: The generative dance between organizational knowledge and organizational knowing. Organization science, 10(4), 381-400.

Cooney, T., Davis, E., and Henderson, K. (1975). Dynamics of teaching secondary school mathematics. Houghton Mifflin.

Cooney, T. J., Shealy, B. E., \& Arvold, B. (1998). Conceptualizing belief structures of preservice secondary mathematics teachers. Journal for Research in Mathematics Education, 29(3), 306-333.

Davis, P., \& Hersh, R. (1981). The Mathematical Experience. Boston: Houghton Mifflin.

Doyle, W., \& Ponder, G. (1977/1978). The practicality ethic in teacher decision-making. Interchange, 8(3), 1-12.

Eggins, S. and Slade, D. (1997). Analyzing casual conversation. London: Cassell.

Ernest, P. (1991). The philosophy of mathematics education. London: Falmer.

Even, R. (1990). Subject matter knowledge for teaching and the case of functions. Educational Studies in Mathematics, 21(6), 521-544.

Fawcett, H. (1938). The nature of proof. Thirteenth yearbook of the National Council of Teachers of Mathematics. New York: Bureau of Publications, Teachers College, Columbia University.

Fenstermacher, G. D., \& Richardson, V. (1993). The elicitation and reconstruction of practical arguments in teaching. Journal of Curriculum Studies, 25, 101-114.

Garfinkel, H., and Sacks, H. (1970). On formal structures of practical action. In J. McKinney \& E. Tiryakian (Eds.), Theoretical sociology: Perspectives and development (pp. 337-366). New York: Appleton-Century-Crofts.

Goffman, E. (1974). Frame analysis: An essay on the organization of experience. Cambridge: Harvard University Press.

Green, T. (1976) Teacher competence as practical rationality. Educational Theory, 26(3), 249258.

Halliday, M. A. K and Matthiessen, M. I. M. (2004). An Introduction to Functional Grammar (Third Edition). Hodder Arnold.

Healy, C. (1993). Build-a-book geometry: A story of student discovery. Berkeley, CA: Key Curriculum Press. 
Herbst, P. (2002). Engaging students in proving: A double bind on the teacher. Journal for Research in Mathematics Education, 33, 176-203.

Herbst, P. (2003). Using novel tasks in teaching mathematics: Three tensions affecting the work of the teacher. American Educational Research Journal, 40(1), 197-238.

Herbst, P. (2006). Teaching geometry with problems: Negotiating instructional situations and mathematical tasks. Journal for Research in Mathematics Education, 37, 313-347.

Herbst, P. and Balacheff, N. (2009). Proving and Knowing in Public: What Counts as Proof in a Classroom. In D. Stylianou, M. Blanton \& E. Knuth (Eds.), Teaching and learning proof across the grades (pp. 40-64). New York, NY: Routledge.

Herbst, P. and Brach, C. (2006). Proving and 'doing proofs' in high school geometry classes: What is 'it' that is going on for students? Cognition and Instruction, 24, 73-122.

Herbst, P. and Chazan, D. (2003). Exploring the practical rationality of mathematics teaching through conversations about videotaped episodes: The case of engaging students in proving. For the Learning of Mathematics, 23(1), 2-14.

Herbst, P. and Chazan, D. (2006). Producing a viable story of geometry instruction: What kind of representation calls forth teachers' practical rationality? In Proceedings of the $28^{\text {th }}$ annual meeting of the North American Chapter of the International Group for the Psychology of Mathematics Education. Merida, Mexico.

Herbst, P., Chazan, D., Chen, C., Chieu, V.M., and Weiss, M. (accepted). Using comics-based representations of teaching, and technology, to bring practice to teacher education courses. ZDMThe International Journal of Mathematics Education.

Herbst, P., Chen, C., Weiss, M., and González, G., with Nachlieli, T., Hamlin, M., and Brach, C. (2009). "Doing proofs" in geometry classrooms. In D. Stylianou, M. Blanton \& E. Knuth (Eds.), Teaching and learning proof across the grades (pp. 250-268). New York, NY: Routledge.

Herbst, P. and Miyakawa, T. (2008). When, how, and why prove theorems: A methodology to study the perspective of geometry teachers. ZDM - The International Journal on Mathematics Education, 40(3), 469-486

Hymes, D. (1977). Foundations in sociolinguistics: An ethnographic approach. London: Tavistock Publications.

Jacobs, J. and Morita, E. (2002). Japanese and American teachers' evaluations of videotaped mathematics lessons. Journal for Research in Mathematics Education, 33(3), 154-175.

Lampert, M. (2001). Teaching problems and the problems of teaching. New Haven, CT: Yale University Press.

Leder, G.C, Pehkonen, E. and Torner, G. (2002). Beliefs: A hidden variable in math ematics education? Dordrecht, The Netherlands: Kluwer.

Leinhardt, G. (1990). Capturing craft knowledge in Teaching. Educational Researcher 19(2), 1825.

Leinhardt, G. and Greeno, J. (1985). The cognitive skill of teaching. Journal of Educational Psychology, 78, 75-95.

Lemke, J. L. (1990). Talking science: Language, learning, and values. Norwood, NJ: Ablex. 
Linde, C. (2001). Narrative and social tacit knowledge. Journal of Knowledge Management, 5, 2, $160-170$.

Mehan, H. (1979). Learning Lessons: Social organization in the classroom. Cambridge, MA: Harvard University Press.

Mehan, H., and Wood, H. (1975). The reality of ethnomethodology. Malabar, FL: Krieger.

Nachlieli, T. and Herbst, P. with González, G. (2009). Seeing a colleague encourage a student to make an assumption while proving: What teachers put to play in casting an episode of geometry instruction. Journal for Research in Mathematics Education, 40(4), 427-459.

Nachlieli, T. and Herbst, P. (2010). Facilitating encounters among teachers with representations of teaching: Two registers. Retrieved on January 12, 2010 from Deep Blue at the University of Michigan, http://hdl.handle.net/2027.42/64852.

Philipp, R. (2007). Mathematics teachers' beliefs and affect. In F. Lester (Ed.), Second Handbook of Research in Mathematics Teaching and Learning. New York: Information Age.

Raymond, A. (1997). Inconsistency between a beginning elementary school teacher's mathematics beliefs and teaching practice. Journal for Research in Mathematics Education, 28(5), $550-576$.

Reath, A. (2006). Agency and autonomy in Kant's moral theory. Oxford: Clarendon Press.

Santagata, R. and Barbieri, A. (2005). Mathematics Teaching in Italy: A Cross-Cultural Video Analysis. Mathematical Thinking and Learning, 7(4), 291 - 312

Schoen, D. (1983). The reflective practitioner. New York: Basic Books.

Schoenfeld, A. (1999). Models of the teaching process. The Journal of Mathematical Behavior, $18(3), 243-261$

Schoenfeld, A. (2006). Problem solving from cradle to grave. Annales de Didactique et de Sciences Cognitives, 11, $41-73$.

Schwartz, J., Yerushalmy, M., \& Wilson, B. (Eds). (1993). The Geometric Supposer: What is it a case of? Hillsdale, NJ: Lawrence Erlbaum Associates.

Senk, S.L. (1989). Van Hiele levels and achievement in writing geometry proofs. Journal for Research in Mathematics Education, 20(3), 309-321.

Sfard, A. (2007). When the rules of discourse change, but nobody tells you: Making sense of mathematics learning from a commognitive standpoint. The Journal of the Learning Sciences, 16(4), 567-615

Shavelson, R.J. and Stern, P. (1981). Research on teachers' pedagogical thoughts, judgments, decisions, and behavior. Review of Educational Research, 51(4), 455 - 498.

Shulman, L. (2000). Teacher development: Roles of domain expertise and pedagogical knowledge. Journal of Applied Developmental Psychology 21(1): 129-135

Silverman, J., \& Thompson, P. W. (2008). Toward a framework for the development of mathematical knowledge for teaching. Journal of Mathematics Teacher Education, 11(6), 499-511.

Smith, B. O., Meux, M., and others. (1962). A Study of the Logic of Teaching. U.S. Department of Health, Education, and Welfare, Office of Education, Cooperative Research Project No. 258- 
(7257). Urbana: University of Illinois.

Speer, N. (2005). Issues of methods and theory in the study of mathematics teachers' professed and attributed beliefs. Educational Studies in Mathematics, 58(3), 361-391

Stigler, J.W. and Hiebert, J. (1999). The teaching gap: Best ideas from the world's teachers for improving education in the classroom. New York: Free Press.

Thompson, A. (1984) The relationship of teachers conceptions of mathematics teaching to instructional practice. Educational Studies in Mathematics, 15, 105-127.

Thompson, A. G. (1992). Teachers' beliefs and conceptions: A synthesis of the research. In D. A. Grouws (Ed.), Handbook of research on mathematics teaching and learning (pp. 127-146). New York: MacMillan.

Thompson, A. G., \& Thompson, P. W. (1996). Talking about rates conceptually, Part II: Mathematical knowledge for teaching. Journal for Research in Mathematics Education, 27(1), 224.

Torner, G. (2002). Mathematical beliefs - A search for a common ground: Some theoretical considerations on structuring beliefs, some research questions, and some phenomenological observations. In G. C. Leder, E. Pehkonen and G. Torner (Eds.), Beliefs: A Hidden Variable in Mathematics Education? (pp. 73-94) Dordrecht, The Netherlands: Kluwer.

Voigt, J. (1985). Patterns and routines in classroom interaction. Recherches en Didactique des Mathématiques, 6(1), 69-118.

Waller, W. (1961). The sociology of teaching. New York: Russell and Russell.

Weiss, M. and Herbst, P. (2007). "Every single little proof they do, you could call it a theorem": Translation between abstract concepts and concrete objects in the Geometry classroom. Paper presented at the 2007 Annual Meeting of the American Educational Research Association, Chicago.

Weiss, M., Herbst, P., and Chen, C. (2009). Teachers' Perspectives on Mathematical Proof and the Two-Column Form. Educational Studies in Mathematics, 70(3), 275-293.

Williams, E. (1979). An Investigation of Senior High School Students' Understanding of the Nature of Mathematical Proof. Unpublished doctoral dissertation. University of Alberta, Edmonton, Canada. 